This is an informal report intended primarily for internal or limited external distribution. The opinions and conclusions stated are those of the author and may or may not be those of the laboratory.

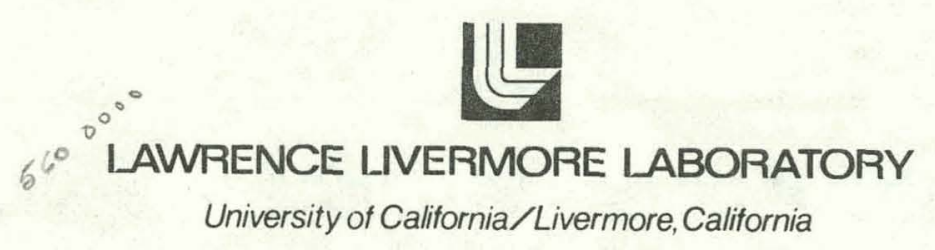

SUGGESTIONS FOR A SUB-MICROSECOND SOFT X-RAY SOURCE

William C. Condit and David A. Nowak

January, 1975

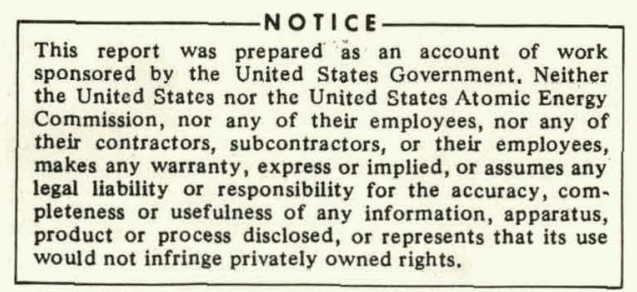

Prepared for U.S. Atomic Energy Commission under contract no. W-7405-Eng-48 


\section{DISCLAIMER}

This report was prepared as an account of work sponsored by an agency of the United States Government. Neither the United States Government nor any agency Thereof, nor any of their employees, makes any warranty, express or implied, or assumes any legal liability or responsibility for the accuracy, completeness, or usefulness of any information, apparatus, product, or process disclosed, or represents that its use would not infringe privately owned rights. Reference herein to any specific commercial product, process, or service by trade name, trademark, manufacturer, or otherwise does not necessarily constitute or imply its endorsement, recommendation, or favoring by the United States Government or any agency thereof. The views and opinions of authors expressed herein do not necessarily state or reflect those of the United States Government or any agency thereof. 


\section{DISCLAIMER}

Portions of this document may be illegible in electronic image products. Images are produced from the best available original document. 


\title{
SUGGESTIONS FOR A SUB-MICROSECOND SOFT X-RAY SOURCE
}

William C. Condit and David A. Nowak

\author{
University of California, Lawrence Livermore Laboratory \\ Livermore, CA 94550
}

January, 1975

\begin{abstract}
It is shown that synchrotron radiation can be considered for a pulsed source of high intensity soft $x$-ray photons by means of a combination of relativistic electron rings with megagauss magnetic field compression technology. Synchrotron radiation is usually obtained in the visible and ultraviolet spectral regions from laboratory particle accelerators, but our calculations show that the compression of electron rings (with their accompanying magnetic fields) inside imploding metal liners should allow us to make compact synchrotron sources of high intensity. The method has the advantage of being efficient (up to $25 \%$ of the energy in a capacitor bank may be convertible to photon output). It can work with existing electron beam machines in the $E=5-15 \mathrm{MeV}$ range, unlike many pellet fusion experiments, which will generally require machines far beyond the present state of the art in energy and energy density. Final1y, our proposed method provides a very flexible $x$-ray source, in that the $5-15 \mathrm{MeV}$ variation in primary electron energy can provide $x$-ray spectra peaked at energies from about $1-30 \mathrm{keV}$. The total number of joules radiated depends only on the energy content of the input electron beam, being 20 times the input for efficient compression. The major uncertainty, which needs to be tested experimentally, is the requirement that the energy density of the electron ring be higher than has yet been achieved.

The above possibilities lead us to suggest the program described in this report. We propose to demonstrate feasibility of electron ring formation and compression with an existing $2 \mathrm{MeV}, 1.5$ kilojoule E-beam machine, plus a capacitor bank liner implosion system. Given the success of this first step, it would be possible to design a facility using a 50 kilojoule E-beam machine, plus auxiliary energy sources for implosion, to provide 100 $\mathrm{kJ}-500 \mathrm{~kJ}$ of kilovolt photon output.
\end{abstract}




\section{INTRODUCTION}

The need for generating intense bursts of soft $x$-ray photons has long been recognized. One well-known source of such $x$-rays, electron synchrotron radiation, is usually not considered for this application because of its low intensity. ${ }^{1}$ In ordinary electron accelerators, such as described in the references, the synchrotron-radiated power comes out over a large area and long periods of time: the machines inherently cannot have a greater radiated power than the input power to their accelerating system. We propose here a technique using imploded-liner megagauss field technology 2,3 to concentrate relativistic electron rings in a very small volume and cause them to radiate large amounts of energy in a very short time, an idea first discussed by Nowak and Shearer. ${ }^{4}$ (This energy is radiated in a restricted solid angle, thus further increasing the intensity.)

The ability of high current electron rings or "E-layers" to form and survive in a proper plasma for long times (thousands of orbits) has been known for almost 10 years. ${ }^{5}$ A schematic apparatus for forming such layers is shown in Fig. 1: electrons are injected on a spiral path into a magnetic field via a pipe (the "inflector"). They are trapped between regions of strong magnetic field (magnetic mirrors) by means of a dissipative interaction with the background plasma or an appropriate resistive layer near the wal1..$^{5}$ If the layer is sufficiently intense and there is a conducting wall around it, the layer will remain centered in the vessel until classical energy loss or scattering causes the individual electrons to be lost, or the layer strength to decay to an unstable level. 6

The energy of the E-layer electrons can be raised by raising the applied magnetic field $B .^{7,8}$ This can be accomplished either by using a 
capacitor bank to provide more ampere-turns in the external coits, or by imploding the metallic liner with explosives, as in Fig. 2, or with a strong magnetic field. ${ }^{3,9}$ As the particle energy increases, proportionally to $B^{1 / 2}$, the synchrotron radiation rate increases dramatically, being proportional to $\gamma^{4} / R^{2}$ or $\dot{B}^{3}$ for an adiabatic compression. Here $\gamma=m / m_{0}=E / m_{0} c^{2}$ is the usual relativistic parameter, assumed much greater than unity. The peak energy of the emitted photon distribution also increases with the compression, being proportional to $\mathrm{B}^{2}$ for the adiabatic case. Thus, by performing a fast compression of an E-Tayer, a short pulse of high energy photons is to be expected. A slot is provided in the center of the liner to permit these $x$-rays to escape: they are concentrated in a narrow angular pancake perpendicular to the axis. ${ }^{1,2}$ The liner-implosion technique has three important advantages: the "wa 11" stays close to the layer throughout, enhancing stability; the attainment of higher fields is possible; and finaliy, the efficiency of the process is greater, since one only provides megagauss-level fields in the small final volume.

We turn now to an analysis of the above process. Section II discusses the radiation from an E-layer. We will introduce there the E-beam parameters for the experiment we suggest. Sections III-V provide a theoretical discussion of the formation, stability and compression of the E-layer. Section VI provides a description of a small-scale demonstration of the E-layer trapping principle. Section VII provides a description of the proposed medium scale imploding-liner experiment. Section VIII provides cost estimates and time tables. 


\section{RADIATION FROM E-LAYERS}

The synchrotron radiation spectrum for a single electron in a circular orbit is well known, and is plotted in Fig. 3 in non-dimensional form. The critical photon frequency and energy are given by $\omega_{c}=3 \gamma^{3}(c / a)$, or in cgs units,

$$
\begin{aligned}
I I .1 \text { (a) } \omega_{c} & =8.38 \times 10^{6} \mathrm{Br}^{2},\left(\mathrm{sec}^{-1}\right) \\
\text { (b) } \hbar_{\omega_{c}} & =3.47 \times 10^{-8} \mathrm{Br}^{2}(\mathrm{eV})
\end{aligned}
$$

where $B$ is in gauss, and $\omega_{C}$ is the characteristic upper frequency for the radiation. The corresponding radius of gyration for a single electron is

$$
a=1.70 * 10^{3} \mathrm{r} / \mathrm{B}(\mathrm{cm})
$$

The time scale for the conversion of the kinetic energy of the electron into radiation is of the order of the energy divided by the power and is given by

$$
11.3 \quad \frac{\gamma}{\mathrm{d} \gamma / \mathrm{dt}} \equiv \tau=5.2 * 10^{8} / \gamma \mathrm{B}^{2} \quad(\mathrm{sec})
$$

where the loss rate is

$$
\text { II.4 } \mathrm{d} \gamma / \mathrm{dt}=-1.94 * 10^{-9} \mathrm{~B}^{2} \gamma^{2}\left(\sec ^{-1}\right)
$$

Let the magnetic field be changed by a factor $\lambda^{2}$; i.e., if the change is induced by an imploding liner, $\lambda$ would be the ratio of the initial radius to the final radius. Then the above quantities would change by the factors given bel ow: 


$$
\text { II.5.a } \begin{aligned}
B & =B_{0} \lambda^{2} \\
\gamma & =\gamma_{0} \lambda \\
a & =a_{0} / \lambda \\
\omega_{c} & =\omega_{c 0} \lambda^{4} \\
\tau & =\tau_{0} / \lambda^{5}
\end{aligned}
$$

We envision an axial compression also, but this only alters the motion along the magnetic field, which is assumed small. Note that the layer behaves like a gas with $\gamma_{g}=3 / 2$. We choose as an interesting example the case $\hbar_{\omega_{c}}=20 \mathrm{keV}, \tau=50 \mathrm{nsec}, \lambda=20$, which we shall follow throughout this work as our reference case. The initial and final conditions are:

$\begin{array}{llcc}\text { II.5.b } & \frac{\text { Initial }}{\text { Magnetic Field B }} & \frac{\text { Final }}{13 \frac{3}{4} \mathrm{kG}} & 5.5 \mathrm{MG} \\ \text { Electron Energy } E_{K}(\mathrm{MeV})=\frac{\gamma}{2} & 7 \frac{3}{4} \mathrm{MeV} & 165 \mathrm{MeV} \\ \text { Orbit Radius a } & 2.0 \mathrm{~cm} & 0.1 \mathrm{~cm} \\ \text { Critical x-ray energy } \hbar_{\omega} & .125 \mathrm{eV} & 20 \mathrm{keV} \\ \text { Characteristic Time } \tau & .17 \mathrm{sec} & 52 \mathrm{nsec}\end{array}$

The total energy, $W$, in the layer depends only on the initial E-layer energy content. We assume a $50 \mathrm{~kJ}$ electron beam machine, and 10\% - 50\% trapping efficiency. This leads to 100-500 kilojoules after compression. We adopt $200 \mathrm{~kJ}$ as our reference case (see Section III for more detailed discussion) The final photon spectrum has its peak at about $0.15 \hbar_{\omega_{c}}$ according to Fig. 3. One might choose other voltages such as the $15 \mathrm{MeV}\left(\gamma_{0} \sim 30\right)$ used in the Aurora machine, where a spectrum with $\hbar_{\omega_{c}}$ of about $50 \mathrm{keV}$ would be 
achieved with $\lambda=20$; alternatively, one could go to $\lambda=30$, or complicated orbits (see below). In short, photon spectra peaked in the keV range with sub-microsecond delivery time seem easily accessible.

For strong electron rings the single electron theory described above needs to be modified. A "strong" Tayer is one in which the layer's diamagnetic current seriously affects the magnetic field. A measure of this is the field reversal parameter $\zeta=\Delta B / B_{V}$, where $\Delta B$ is the jump in field across the layer and $B_{V}$ is the "vacuum" field present before the layer is introduced. In general one adjusts $B_{V}$ so that $a_{0}=\gamma_{0} \mathrm{mc} / B_{V} q$, so that the layer is injected at the equilibrium radius ( $q$ is the electron charge). To allow for the possibility of a plasma current in the opposite direction to the layer current, commonly called "current neutralization", we distinguish between $\zeta_{L}=\mu_{0} I_{E} / L B_{0}$ as a measure of the $\Delta B$ due to the layer alone, and $\zeta=\zeta_{\text {net }}=\mu_{0}\left(I_{E}-I_{P}\right) / L B_{0}$ based on the total current where $B_{0}$ is the average $B$ field. For our example with $10 \mathrm{~kJ}$ initial, $200 \mathrm{~kJ}$ final, this return current is necessary - see Section $V$.

If $\zeta_{\text {net }}=0(i)$, the electron orbits will in general no longer be circular, but will oscillate about the mean radius of the layer with an amplitude of order of but less than the thickness of the layer (see Fig. 4). It is these oscillations which determine the radiation spectrum. They have the effect of hardening the radiation spectrum over that which arises from purely circular motion.

\footnotetext{
Although $\zeta_{\text {net }}$ is dependent on the fraction of current neutralization and also time dependent for a less than perfectly conducting plasma, $\zeta_{L}$ is
} 
dependent only on the number of electrons per unit length, $N^{\prime}$, and is related to the kinetic energy, $W_{K}$, per unit length $(L)$ of the $E$-layer by

II.6 $\quad W_{K} / L=14.54 \zeta_{L} \gamma^{2} \quad(J / M)$

where $\gamma \gg>1$. The required $\zeta_{L}$ is thus given, for a synchrotron source, by the energy content and size of source required. The E-layer will radiate into an angle of $\pm 1 / \gamma$ of the plane of the orbit, according to simple theory. ${ }^{2}$ When the final $\gamma$ is of the order of 100 or more, this is an extremely small angle. The axial betatron oscillations, however, broaden this angle, and involve typically, $v_{z}=.10 \mathrm{C}$ at the midplane of the coil, as shown in Fig. 5. The net result is that we should be able to put all the synchrotron radiation from a $1 \mathrm{~cm}$ long layer onto a $10 \mathrm{~cm}$ wide annular strip at up to $50 \mathrm{~cm}$ from the source. Using an electron layer energy of $200 \mathrm{~kJ}$ with $\gamma_{f}=$ 323, we find $\zeta_{L}=13.2$ from II.6. This should be easily achieved for $R_{\text {wal1 }} / R_{\text {layer }}=1.5$ or less and with partial current neutralization (see Ref. 10, Eq. 33). With the conducting wall at a large radius, (as in a capacitor bank compression near maximum B), the largest possible value of $\zeta$ is 2 , so we see an advantage of liner implosions: they permit more joules/ unit length of source by letting the wall follow the layer in.

With a final value of $\zeta_{L}=13.2$ and radial compression with $\lambda=20$, the initial value of $\zeta_{L}=264$. Even with the assumed axial compression of $20: 1$, the initial value would be back to 13.2. This, of course, requires nearly complete current neutralization. This level of E-layer energy density has not been attained as yet, although there is no known theoretical reason why it cannot be attained. It is equivalent to $\mathrm{v} / \mathrm{\gamma}=$ 6.6 for a propagating beam. We propose to attain it by a combination of 
efficient E-layer trapping and axial compression of the layer after it is trapped, plus a large radial pressure gradient set up by the auxiliary Z-pinch shown in Fig. 2a. We emphasize that if these efforts are unsuccessful, one can still get the desired $100 \mathrm{~kJ}-200 \mathrm{~kJ}$ outputs by firing several modules with $\zeta_{L}=2-3$, which is certainly attainable.

One problem which must be faced is that the scaling of $\gamma$ with radius given by II.5 is not exact as the electrons radiate during the run-in phase of the implosion. For realistic rise time of the magnetic field, it is necessary to consider the time-dependent spectrum of the synchrotron radiation - this can be obtained by solving the following equation:

$$
\text { II.7 } d \gamma / d t=-c_{1} B^{2} \gamma^{2}+(\gamma / 2 B) d B / d t
$$

Here the second term represents the adiabatic compression and the first term is the synchrotron loss $\left(c_{1}=-1.9 \times 10^{-9} \mathrm{sec}^{-1}\right.$ gauss ${ }^{-2}$. This equation is valid in the limit $\left.\zeta_{\text {net }} \ll 1.\right)$.

A set of values of the maximum value of $\omega_{C}$ and final $\tau$ for a run-in from $R_{L i}=2.00 \mathrm{~cm}, R_{W i}=2.83 \mathrm{~cm}$ in times $T_{0}$ from 26 microseconds to 1 microsecond is given in Table $I$. We conclude that run-in velocities of about $1 \mathrm{~cm} / \mathrm{microsecond} \mathrm{are} \mathrm{needed} \mathrm{to} \mathrm{achieve} \mathrm{even} 25 \%$ of the ideal values from II.5. Again, the detailed effect of the betatron orbits, and possible re-absorption of the synchrotron radiation at early stages, needs to be computed. It is to be emphasized, however, that velocities of $1 \mathrm{~cm} / \mathrm{microsec}$ can be achieved with appropriate liners .

\section{TRAPPING THE E-LAYER}

When an electron beam is injected on a spiral path into a magnetic field, as in Fig. 1 , there are several means by which the individual 
electrons can be trapped between the magnetic mirrors. Efficient trapping is important because the E-beam energy is the most expensive portion of the energy input to the system, even though it is a small fraction $(1 / \lambda)$ of the total input energy. Conservation of energy and canonical angular momentum would, of course, allow the particles to return to their point of origin and be lost on the injection pipe, in a time-independent field. We therefore must think of dissipative trapping processes or of varying the mirror strength rapidly. One might start with a low mirror value (say 14.3 kilogauss ${ }^{*}$ for the mid plane field in II.5.b) and raise it to a higher value (say 18.3 kilogauss $^{\star *}$ ) in a time comparable with the electron pulse injection time, which is 50-100 nanoseconds for conventional machines. This would require 11-22 kV for a $6 \mathrm{~cm}$ coil diameter which might reasonably go with the parameters of II.5.b. With the injected pulse having an axial velocity of $.2 \mathrm{c}$, the resulting layer would be 3 meters long for a 100 ns pulse (folded back on itself in the mirror), and would have to be post-compressed axially to the $2 \mathrm{~cm}-4 \mathrm{~cm}$ length required for implosion. While such a technique offers a straightforward method of trapping nearly all the electrons produced by the E-beam machine, the difficulties of handling the requisite voltages in the presence of a background plasma, and the difficulties of post-compression, make us view this technique as an adjunct to the dissipative trapping schemes.

Historically, the resistive-layer trapping mechanism, sketched in Fig. 1 , was the first to be used. ${ }^{5}$ We wi 11 estimate the resistive drag using long-layer theory. In principal one can extract twice the transient mag-

\footnotetext{
* Corresponding to passing an injected parallel velocity of .2c $\left(R_{m}=1.04\right)$ therefore trapping all electrons up to $v_{z}=.5 c\left(R_{m}=1.33\right)$.
} 
netic energy stored between the resistors and the wall as the pulse passes. Fesseriden and Stallard have shown that one actually gets about $1 / 2$ the amount based on long-layer theory for realistic pulse shapes. ${ }^{12}$ They show that the energy comes out of the axial motion. The spiral motion of the beam is usually washed out in one or two turns by the spread in $v_{z}$ of the beam electrons, 13 so the "travelling E-layer" acts like the moving primary of a transformer, with the resistors being the secondary. We will assume the layer length is $20 \mathrm{~cm}$. The ratio of magnetic to kinetic energy for such a layer can be shown to be $(\zeta / 4)\left(1-R_{E}^{2} / R_{W}^{2}\right)$, and some small fraction of this is stored behind the resistors. On the other hand one need only extract a fraction $v_{z}^{2} / 2 c^{2}$ of the total kinetic energy to bring the layer to rest. Thus a placement of the resistors to intercept about $8 \%$ of the layer magnetic energy will allow a $\zeta_{\text {net }}=1$ layer, injected at $v_{2}=.2 c$ with $R_{W}=\sqrt{2} R_{E}$, to stop in a distance equal to its own length, according to ideal theory! The calculations of Fessenden and Stallard suggest that one will need about twice this distance for $\zeta_{\text {net }}=1$, and this would give a $40 \mathrm{~cm}$ stopping length. The case $R_{W}=\sqrt{2} R_{E}$ is convenient for injection and stability, and has the property that the transient magnetic energy density is the same inside and outside the layer. Thus to meet the criterion of $8 \%$ of the energy being in the $\Delta R$ between the resistors and the wall, we need $2 \Delta R / R_{W}=.08$, or $\Delta R=.11 \mathrm{~cm}$ for $R_{W}=2.82 \mathrm{~cm}, R_{E}=2 \mathrm{~cm}$ from II.5.b. The resistivity of the layer is to be adjusted to give the resistive layer an $L / R$ time comparable to the pulse injection time. ${ }^{12}$ Detailed calculations remain to be done, but the dimensions given above, including the e-folding length for stopping, should be very close to the truth, and can in any case be achieved with minor modifications to $\Delta R$. 
An even simpler method of trapping the beam has been described by Rostoker and $\mathrm{Chu}^{13}$ They show that in an appropriate weakly collisional plasma the electrons at the front of the e-layer have a reciprocal range, $R^{-1}$, given by

$$
\text { III.I } \quad R^{-1}=\frac{2 F_{z}}{\gamma m v_{0}^{2}}=\frac{2 n_{b} v_{e}}{r_{0} n_{0} v_{0}}\left(\frac{v_{\perp}^{2}}{v_{0}^{2}}\right)
$$

Here $v$ is the collision frequency, $n_{b}$ and $n_{0}$ are particle densities for the e-layer and plasma respectively, and $V_{0}$ is the axial velocity. A discussion of the derivation of III.1 is given in Appendix A. It is shown there that in a reasonable plasma $\left(n_{e}=1.52 * 10^{15}, T_{e}=8 \mathrm{eV}\right)$, the braking length can be made of the order of $40 \mathrm{~cm}$ for our sample layer with $\zeta_{L}=13.2$ and $V_{0}=.2 \mathrm{C}$.

For either the resistor or plasma trapping mechanism, a final magnetic mirror is needed to center the layer in the liner. This is shown in Fig. $2 b$. Assuming an injection velocity of .2c in the axial direction, and one e-fold down to $.0736 \mathrm{c}$, the mirror ratio required to trap the layer is only 1.005 ! Actually, this means that small field errors will have a serious effect on the layer, so a slow-pulsed field will probably be added to center the layer, as shown in Fig. $2 b$.

We may conclude, and past experience at LLL and Cornell University bears this out, that 10\%-50\% (or more) of the injected E-beam electrons wi 11 be trapped by a carefully designed sys tem.

\section{STABILITY OF THE LAYER}

The stability of electron rings and layers received considerable attention at Livermore during the Astron project. ${ }^{5,6,7}$ There are several 
possible instabilities, but at this time all of the observed ones can be stabilized or avoided by we11-known. means.

The fastest growing and potentially most damaging instabilities are hydromagnetic in nature, such as the so-called "tearing mode". This is a tendency for a layer with an axial perturbation to tear itse if up into a series of rings, due to the magnetic self-pinch force. The sequence of events is shown in Figs. $6 a, 6 b, 6 c$. The rings tend to coalesce into a new and stable distribution. This process of tearing apart and reassembling was regularly observed in the Livermore Astron experiments - so long as adequate mirrors are provided to contain the individual rings, they will reassemble. ${ }^{12}$ The tearing mode is closely related to the filamentation instability for a straight beam, ${ }^{18,23}$ where the reassembly has been observed in computer simulations, and theoretically analyzed.

Another class of instabilities is the set of so-called "precessional modes". The betatron oscillations shown in Fig. 4 become unstable in the presence of resistive wal $1 s^{14}$ or plasma with finite resistivity. ${ }^{15}$ Fortunately, for an E-layer which is space-charge neutralized, these instabilities are eliminated by the image currents in the walls at high enough E-layer current levels (specifically, $\zeta>f_{0} / f_{m}$, as given by Eq. IV.I of Ref. 6, and subsequent discussion). For our case, this requires $\zeta>.04$, as calculated in Appendix $B$. This is easily achievable in the initial E-layer. ${ }^{16}$ However, as the implosion proceeds, the E-layer length/diameter increases, whi le $\zeta$ decreases, as shown in the next section. For this reason, among others, we choose not to count on wall stabilization; and we elect to put a small toroidal field in the 
device by means of a $0.5 \mathrm{~mm}$ diameter current-carrying rod down the axis of the device. ${ }^{17}$ One then requires

$$
\text { IV. } \quad \Omega_{\theta} / \Omega_{z}>n_{M}^{1 / 2}
$$

where $\Omega_{\theta}, \Omega_{z}$ are the cyclotron frequencies based on $B_{\theta}, B_{z}$ respectively, and $\eta_{M}=\left(R_{M} / B_{M}\right)\left(d B_{M} / d R\right)$ due to the external mirror field. For the field shape of Fig. $2 b, \eta_{M}=.0133$ from Appendix $B$. We thus require $B_{\theta}>.11 B_{Z}$ throughout the implosion. This condition is most severe at maximum compression, where $B_{z \max }=5.5$ megagauss and $R=0.1 \mathrm{~cm}$. The current

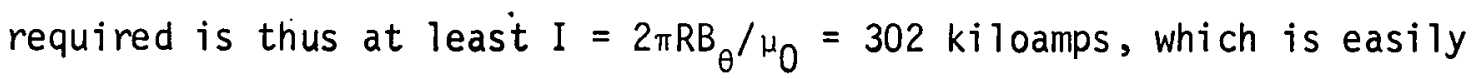
attainable, assuming $6 \mathrm{kV}$ drive voltage, inductance $10^{-7}$ henry, and risetime 5 microseconds. The actual current required will be less than this at the end of the implosion due to the intrinsic stabilizing effect of the metal center rod, as explained in Appendix B.

The final class of instabilities is the so-called micro-instabilities such as negative mass ${ }^{19}$ and the upper hybrid mode beam-plasma resonances. 20 These instabilities quench themselves by non-linear processes after an initial growth phase, are usually absent in the presence of suitably dense plasmas, and in any case involve little E-layer loss. 21

We can summarize by saying that all known instabilities of the E-layer either have a well-known cure (such as the precessional instabilities), or have non-linear saturation or quenching levels which prevent them from destroying the layer.

\section{COMPRESSION OF THE LAYER}

It is well known that when a magnetic field is increased in time, the canonical angular momentum of any electron in this field is a constant of 
the motion. 22 This is true even if the self-fields of the layer are included, as long as they are symmetric. ${ }^{7}$ G. Schmitt has shown that $P_{\theta}=-q_{0} R^{2} / 2$. This leads to the scaling law $\mathrm{Ba}^{2}=$ constant, which was used in II.5.a. Further, the work of Ref. 7 can be trivially extended to show that if $\zeta_{\text {net }} \ll 1$, then $\gamma$ is proportional to $1 / a$. Since the layer energy content is proportional to $\gamma$ and since the energy content

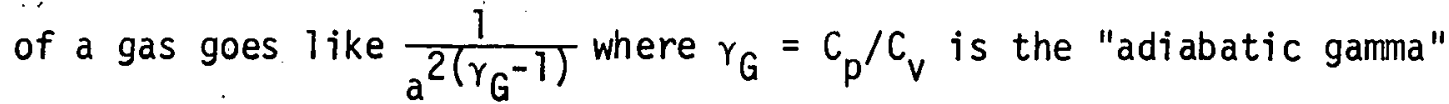
in a cylindrical compression, we conclude that the E-layer behaves like a gas with $\gamma_{G}=3 / 2$ in the weak-layer or current neutralized case. We intend to run our experiments nearly or completely current neutralized, so this is an appropriate assumption. The decay of the neutralizing current during the implosion can be made negligible (see below). The centrifugal pressure of the layer has the appropriate behavior $\left(1 / a^{3}\right)$. In the limit $\zeta_{\text {net }}>>1$, the behavior will be quantitatively slightly different, but qualitatively similar; as far as the imploding liner is concerned, the E-layer acts like a gas to be compressed.

The design of the implosion system then hinges on picking the desired compression ratio, $\lambda$, and making sure that the stability criteria are met throughout the implosion. Since the E-layer self-field goes up only as $1 / a$, while the field it is attempting to reverse goes up as $1 / a^{2}$, the value of $\zeta_{L}$ decreases in a purely radial compression. To achieve a final $\zeta_{L}=13.2$ with a reasonable value of $\lambda$ equal to twenty, ${ }^{24}$ we would need an initial value of $\zeta_{L}=264$. Such a value is impossible 10 without either a strong toroidal field or a complete absence of neutralizing plasma, ${ }^{26}$, both of which would be difficult to implement in our case due to the problems in injecting large currents. Alternatively, one can have nearly complete electric and magnetic neutralization, so that the 
limits of Ref. 10 do not apply. One must supply a plasma pressure gradient to balance the E-layer centrifugal force. We choose the latter path. Following Ref. 10 with appropriate modifications for the current neutralization, we assume the net field reversal must not rise about $=4$ during the $\left(T_{j}=2.7\right.$ microsecond $)$ implosion. Since the plasma return currents are decaying with an $L / R$ time constant toward $\zeta=264$, we must have $L / R$ much greater than $66 \mathrm{~T}_{i}=178$ microseconds. Using a layer radius of $2.00 \mathrm{~cm}$, thickness $0.4 \mathrm{~cm}$, we find that a plasma temperature of $100 \mathrm{eV}$ is adequate to ensure this slow decay. The plasma heating by the E-beam should be enough to ensure this. ${ }^{13}$ The plasma density is arbitrary, except that it must exceed the beam density in order to space-charge-neutralize the beam (requiring somewhat above $7.6 * 10^{13} \mathrm{e}^{-} / \mathrm{cc}$ for the highest case - the $25 \mathrm{~kJ}$, $20 \mathrm{~cm}$ long E-layer shown in Fig. 2). It must also not be dense enough to cut off the $x$-rays at peak compression, but for a hydrogenic plasma this only requires that the initial density be below $10^{21}-10^{22} \mathrm{e}^{-} / \mathrm{cc}$, a limit which is far beyond that set by plasma containment requirements at $100 \mathrm{eV}^{\star}$. Picking $n_{\mathrm{e}}=15.2 * 10^{14} / \mathrm{cc}$, the plasma pressure is .4863 atmosphere at $100 \mathrm{eV}$, which is easily contained by the 13.75 kilogauss field. The plasma confinement will be stable due to the combination of the mirror and toroidal field, plus the residual layer field.

The twenty-fold axial compression is an option, but it is useful to bring all the electrons into the radiating gap, and it reduces the $\zeta$ problems discussed above. Part will be done by pulsing the axial compression coil and part will be done by shaping the implosion. An overall time-sequence of the magnetic field behavior is shown in Fig. 7. The mirror ratio goes from

\footnotetext{
${ }^{\star}$ Note: Another limit of about $10^{18} / \mathrm{cc}$ is set by classical scattering during the implosion.
} 
1.33 initially to about 3 at the end. We have assumed, for the purposes of this figure, that the layer and background plasma compress together as a fluid with $\gamma_{G}=1.5$. Actualiy, the background plasma will have a slightly different behavior $\left(\gamma_{G}=1.67\right)$, and we will, of course, incorporate this into future calculations. The radial pressure gradient will be provided by an axial current which rises from $700 \mathrm{KA}$ to $14 \mathrm{MA}$ during the implosion. This technique has been demonstrated in E-beam propagation experiments. 30

\section{A SMALL-SCALE LABORATORY DEMONSTRATION EXPERIMENT}

The initial effort would be confined to the demonstration of the feasibility of compressing E-layers and the investigation of the scaling necessary to achieve a useful source for simulation purposes. This would include the following.

1. The theoretical and experimental investigation of the formation of intense $E$-layer $\zeta_{L}>1$ in a geometry suitable for use as a radiation source.

2. The theoretical and experimental investigation of the effects of partial current neutralization on the compression and radiation spectrum of the E-layer.

3. The production of kilojoules of photons with maximum energy in the 0.1 to $1 \mathrm{keV}$ range as a demonstration of the feasibility of the concept.

The fundamental fact confronting any attempt to design a small-scale experiment is the strong $\gamma$ dependence of emission frequency and radiation rate, shown by II.I and II.4. It therefore seems to us that we should abandon the hope of producing kilovolt x-rays in the initial, small- 
scale experiment, since there is very little question about the theory presented in Section II. Instead we propose to tackle the problems of E-layer formation and compression in relatively small geometries, such as implied by II.5.b. We will try to observe the radiation, but it will be very soft.

We expect to have available a 2 MeV-25 kiloamp E-beam $(\gamma=5,30 \mathrm{~ns}$ pulse FWHM). We choose to use larger dimensions than in II.5.b, namely, $R_{L}=$ $4.25 \mathrm{~cm}, R_{W}=6 \mathrm{~cm}, L_{\text {initial }}=20 \mathrm{~cm}$. Equation II.6 tells us that if we trapped all of the one-and-a-half kilojoules of electrons, we would achieve $\zeta_{L}=20$. The field required by the particle energy and radius is 2 kilogauss, requiring 200 joules of initial magnetic energy in the $40 \mathrm{~cm}$ long guide field. The amount contained within the liner is 72 joules, and we propose to compress with $\lambda=20$, leading to a compressed magnetic energy of $28.8 \mathrm{~kJ}$. The $E-l a y e r$ energy will increase by $\lambda$ to $30 \mathrm{~kJ}$. The plasma energy is small compared to these energies since only. $40 \mathrm{eV}$ initial temperature is required. Magnetic liner implosions are calculated to have total efficiences of $60 \%-70 \%$ for the energy delivered to the volume being compressed (fields plus particles inside). Thus one can take $120 \mathrm{~kJ}$ as a moderately conservative estimate of the energy required to drive the magnetic implosion. We find that a one-stage implosion system is adequate to get the velocities needed for this preliminary experiment. A computer calculation of the proposed implosion dynamics starting from radius at which velocity is a maximum is shown in Fig. 8. Here we have assumed $\gamma_{G}=1.67$ for all matter inside the 1 iner. The drive-energy requirement is confirmed by this calculation (25\% should be added to the calculation for losses in the bank and leads, which were not included). 
The required implosion velocity is less for this case than for II.5.b, by roughly the fifth power of the ratio of the $\gamma^{\prime} s$, since synchrotron radiation has much less tendency to rob the layer energy in this case (see Table II). We have thus chosen $U_{i}=.316 \mathrm{~cm} / \mathrm{microsecond}$. The corresponding ideal parameters initially and at maximum compression are:

VI.1 Initial Final

$\begin{array}{cccl}\text { a } & 4.27 & .21 & \mathrm{~cm} \\ \mathrm{E} & 2.04 & 50.1 & \mathrm{MeV} \\ \mathrm{B} & 2 \times 10^{3} & 8 \times 10^{5} & \text { gauss } \\ \hbar \omega_{\mathrm{C}} & 1.7 \times 10^{-3} & 2.78 \times 10^{2} & \mathrm{eV} \\ \tau & 26.0 & 8 \times 10^{-6} & \mathrm{sec}\end{array}$

The dwell time of the liner around minimum radius can be estimated as 2.4 $\left(R_{\min } / U_{i m p l o s i o n}\right)=1.7$ microseconds, and it can be made somewhat longer. 27 Thus the characteristic 8 microsecond radiation time shown in VI.I will allow a sizable fraction of the layer energy to be radiated during the liner dwell time. From VI.I and Fig. 3, the peak photon energy will be at $.15 h_{c}=41.5 \mathrm{eV}$ (about $300 \mathrm{~A}^{\circ}$ - in the vacuum UV). These photons should be readily observable in the kilojoule quantities which we expect, although, as stated above, this would not be the primary aim of the first experiment. It is important to keep in an area where synchrotron radiation is significant, even if unobserved, to duplicate the final layer dynamics on a reduced scale. ${ }^{28}$

A schematic layout of the $2 \mathrm{MeV}$ initial experiment is shown in Fig. 9. 


\section{THE MAIN EXPERIMENT .}

The parameters of the main experiment have been given in II.5.b. As above the energy content of the layer is determined by the desired output. We pick 200 kilojoules as a target number. The magnetic energy content is calculated in Appendix C. The large implosion velocity required leads us to the two-stage magnetic implosion shown in Fig. 2. Thus, to supply up to 200 kilojoules to compress the E-beam, and about 900 kilojoules to compress the magnetic field, at the outer shell we need on the order of 4.4 megajoule to drive the inner shell at $25 \%$ overall efficiency. The 14 megamp axial current requires an energy of 1.35 megajoules in a lowinductance bank. We have picked $M_{2}=.25 M_{1}$ to get good velocity multiplication $\left(V_{2}=1.6 V_{0}\right)$ while stitl retaining a sizable mass for the inner liner. The energetic efficiency is $E_{2} / E_{0}=64 \%$ based on momentum transfer alone, and some allowance must be made for magnetic dissipation and liner internal energy losses. To be conservative, one would have to take 5.6 megajoules as the total energy required for the "al1-out" $500 \mathrm{~kJ}$ yield. We would want to start with the reference yield of $200 \mathrm{~kJ}$ of radiation (about 4.4 megajoules in the drive source), and this is what we will base our further calculations and cost estimates on. A I-D computer calculation of the performance of this implosion system is given in Fig. 10. We are preparing a 2-D computer code which will allow the details of the liner motion around the window guards to be computed. (This code is being prepared for other purposes, and should be available within 6-10 months).

It is entirely possible that chemical explosives may offer the cheapest way to drive the outer shel1. (3) They typically have overall efficiencies on the order of $10 \%$, however, so the amount of energy 
required goes up from 4.4 to 11 MJ (about 6 lbs of TNT equivalent). The problems of shielding the E-beam machine against such a blast would be formidable; but perhaps cheaper than buying a large capacitor bank. The amount of steel for containment is about 2400 lbs. An alternative would be to use inductive energy storage devices or explosive generators located well away from the machine to provide the large energy pulses required. Explosive generators are relatively well developed - however their use entajis an expenditure of thousands of dollars per shot, so the breakeven point for a capacitor bank or inductive storage unit is reached in a few hundred shots.

General design sketches of the proposed facility are shown in Fig. 11. Cost estimates are discussed in Section VIII and summarized in Tables IVA, IVB.

\section{COST ESTIMATES AND TIME SCHEDULES}

Cost estimates for the initial experiment are given in Table IIIA: the facility cost would be around $\$ 357,000$, assuming installation at LLL in Building 341 . This could be cut by $\$ 40 \mathrm{~K}$ if detailed observation of the UV emission is not required. It could be cut by an additional $\$ 20 \mathrm{~K}$ if shadow-shielding assumed in the installation estimate can be avoided by beefing up the vault walls during planned FY75 reconstruction. $\$ 297,000$ seems like the minimum facility investment required.

Tabie IIIB shows an estimate of a facility using direct capacitor bank compression of the layer. The costs are very large, due to the large volume which must be filled with magnetic field. 
The direct personnel involved on the experiment should be augmented by two physicists doing computational/theoretical work. Again, if this involves sacrificing the detailed UV observations, which I have rated at 1 physicist and 1 technician in Table III, that would be an option. One could thus run the program on a total of 8 committed people and 2 general support allocations. Should the low-level $6 \mathrm{MeV}$ experiments be desired on the Astron accelerator, ${ }^{28}$ one should budget an additional $\$ 200 \mathrm{~K}$ operating expenses, and $\$ 200 K-\$ 300 K$ set-up costs.

The saving incurred by not having to make a liner for each shot are not significant, compared with the operating costs of the large capacitor bank.

The requirements for the main facility are shown in Table IV. These are to be regarded as preliminary estimates, but are probably accurate to $\pm 30 \%$. The HE-imploded system shown in Table IVB requires the least capital investment, but its operating expenses are considerably higher. Considering the possibility of making a full-scale kilovolt $x$-ray simulator, we feel that the rewards wi 11 justify the admittedly sizable costs.

We would suggest that work be started in mid-FY75 on installation of the initial experiment, at the level indicated in Table IIIA. We estimate about 1.5 years at this level, followed by about 2 years at the level of Table IVA or IVB, as selected, After that, the facility would presumably go into an operating mode at about $3 / 4$ the operating costs shown in IVA or IVB. 


\section{REFERENCES}

1. M. L. Perlman, E. M. Rowe, and R. F. Watson, "Synchrotron RadiationLight Fantastic", Physics Today 27, No. 7, 30 (July 19.74).

F. R. Elder, R. V. Langmuir, H. C. Buock, Phys. Rev. 7452 (1948).

D. H. Tomboutian and P. L. Hartman, Phys. Rev. 1021423 (1956.L.

2. C. M. Fowler, Science 180261 (1973).

3. J. W. Shearer, et a1., Explosive-Driven Magnetic-Field Compression Generators, J.A.P. 39 2102 (1968).

4. D. A. Nowak and J. W. Shearer, "Multimegajoule Soft $X-$ Rays from Compressed Electron Layers" (SRD), LLL Internal MemorandumCOPD 74-59, May 14, 1974.

5. N. C. Christofilos, UCRL-12303 (1964).

6. J.W. Beal, et al., in Plasma Physics and Controlled Nuclear Fusion Research (Novosibirsk Proceedings 1 967) 1969, IAEA, Vienna.

7. G. Schmidt, Phys. Flu. 151540.

8. N. C. Christofilos, LLL Report UCRL-50002-71.

9. J. P. Boris, R. A. Shanny, and N. K. Winsor, Bull. Am. Phys. Soc. Y7 1029 (1972).

10. M. E. Reinsink, Phys. Flu. 16, 443 (19.73). The equation applies to partially current-neutralized cases with $\zeta=\zeta_{\text {net }}$.

11. Lichtenberg, Phase Space Dynamics of Charged Particles.

12. B. W. Stallard and T. J. Fessenden, UCRL-74777 (to be published in Phys. Flu. 1964).

13. K. R. Chu and N. Rostoker, Phys, Flu. 17813 (1974).

14. H. P. Furth, Phys. F7u. 82020 (1965).

15. H. L. Berk and R. N. Sudan "E-Layer Precession in a Plasma" IC-70-116, August 1970.

16. Andrews, et a1., Phys. Rev. Lett. 26295 (1971).

17. N. C. Christofilos, et al., Plasma Physics and Controlled Nuclear Fusion Research (Madison) IAEA, 1971, Vol. I, p. 179. 
18. R. Lee and M. Lampe, Phys. Rev. Letters 311390 (1973).

19. V. K. Neil and R. W. Landau, Phys. Flu 92412 (1966)

20. T. J. Fessenden and B. W. Stallard, Observations of the Hybrid Mode, UCRL-50002-70, p. 3-27.

21. W. C. Condit, et a1., (Ibid., p 3-31).

22. B. Lehnert, Dynamics of Charged Particles, North Holland, Amsterdam, (1964), p 232 .

23. G. Benford, Bul1. Am. Phys. Soc. 181284 (1973).

24. J. Nuckolls, J. Emmett, and L. Wood, Physics Today 2646 (1973), give $\lambda=20+$.

25. The phenomenon of a back-current flowing in a plasma when an electron beam is put into it is well known. See D. Hammer and N. Rostoker, Bul1. Am. Phys. Soc. 13 p. 1571, paper 7E4, or R. N. Sudan and R. V. Lovelace, Phys. Rev. Letters 271256 (1971), Ref. 13 is the first comprehensive treatment of this phenomenon for a rotating beam in an axial magnetic field.

26. Electron Beam Storage Devices for Controlled Fusion, N. Rostoker, Abstract \#36, N.Y. Academy of Sciences, New York, N.Y., April 4, 1974.

27. W. Condit, A Parameter Study of Liner Implosion for Possible CTR Applications, LLL Publication, UCID-16474 (January, 1974).

28. Should it be desirable to study electron dynamics at the $6 \mathrm{MeV}$ level, one can conceive of a small electron-ring experiment using the 600 amp Astron accelerator as the source, and an electron ring compressor similar to the one used by the LBL Electron Ring Accelerator group in 1969. One should be able to observe the synchrotron radiation, and perhaps the effect of betatron oscillations on it. However, since there is little difference in principle between $2 \mathrm{MeV}$ and $6 \mathrm{MeV}$ electron dynamics ( $r \gg>1$ in both cases), and since it is not clear that facility arrangements could be made, we are not pursuing this at present.

29. L. Spitzer, Physics of Fully Ionized Gases, Interscience, N.Y., 1962, Eq. 5. 42 ).

30. J. Benford and B. Ecker, Phys. Rev. Letters 261160 (1971). 


\section{TABLE I}

\begin{tabular}{|c|c|c|c|c|}
\hline $\mathrm{T}_{0}(\mu \mathrm{sec})$ & $V_{0}(\mathrm{~cm} / \mu \mathrm{sec})$ & ${ }_{\mathrm{c}}^{{ }_{\mathrm{c}}(\mathrm{keV})}$ & $\tau(\mu \mathrm{sec})$ & $\underline{\lambda}$ \\
\hline 26.3 & 0.10 & 0.68 & 1.40 & 11.8 \\
\hline 15.0 & 0.18 & 1.15 & 0.79 & 13.1 \\
\hline 8.5 & 0.32 & 1.93 & 0.46 & 14.4 \\
\hline 4.8 & 0.56 & 3.14 & 0.25 & 16.3 \\
\hline 2.7 & 1.00 & 4.93 & 0.16 & 17.6 \\
\hline 1.6 & 1.78 & 7.33 & 0.11 & 18.7 \\
\hline 0.9 & 3.16 & 10.3 & 0.08 & 19.85 \\
\hline 0 & $\infty$ & 20.0 & 0.05 & 20.0 \\
\hline
\end{tabular}

The above values are for a weak E-Layer with initial conditions given in II.5.b. $V_{0}$ is the initial velocity of a liner at radius $\sqrt{2}$ a. $T_{0}$ is the implosion time. 


\section{Table II}

$\begin{array}{cccc}\frac{T_{0}(\mathrm{sec})}{5.80 \times 10^{-3}} & \frac{V_{0}(\mathrm{~cm} / \mathrm{sec})}{1.0 \times 10^{3}} & \frac{{ }_{{ }_{C}}(\mathrm{eV})}{6.8} & \frac{\tau(\mathrm{sec})}{3.2 \times 10^{-4}} \\ 1.83 \times 10^{-3} & 3.16 \times 10^{3} & 2.0 \times 10^{1} & 9.2 \times 10^{-5} \\ 5.80 \times 10^{-4} & 1.0 \times 10^{4} & 5.2 \times 10^{1} & 3.1 \times 10^{-5} \\ 1.83 \times 10^{-4} & 3.16 \times 10^{4} & 1.2 \times 10^{2} & 1.5 \times 10^{-5} \\ 5.80 \times 10^{-5} & 1.0 \times 10^{5} & 1.9 \times 10^{2} & .1 .0 \times 10^{-5} \\ 1.83 \times 10^{-5} & 3.16 \times 10^{5} & 2.4 \times 10^{2} & 9.0 \times 10^{-6} \\ 5.80 \times 10^{-6} & 1.0 \times 10^{6} & 2.7 \times 10^{2} & 8.3 \times 10^{-6} \\ 0 & \infty & 2.9 \times 10^{2} & 8.1 \times 10^{-6}\end{array}$

Similar to Table I except that the above values are for a weak E-layer with initial conditions given in VI.1. 
Table IIIA

PHASE I (INITIAL EXPERIMENT): LINER OPTION

Facility Costs:

Use LLL Machine (P/I \#316)

Field Coils

Implosion Coils

120 kJ Implosion Bank

Vacuum UV Diagnostics

8 Oscilloscopes + Screen Room

Machine Shielding + Installation

$$
\begin{gathered}
\$ 2,000 \\
15,000 \\
120,000 \\
40,000(1) \\
85,000(1) \\
\frac{95,000}{\$ 357,000}
\end{gathered}
$$

Personnel Required:

1 Project. Leader

2 Facility Technicians

1 Diagnostic Technician

1 Experimental Physicist

2 Facility Engineers

2 Heads Miscellaneous Support

3 Theoretical Physicists

4 Heads Engineering Design/Fabrication

Estimated Operation Costs: (2)

500 Liners (4/day * 125 Operating days)

(c) $\$ 200$ ea. (3) $^{(3)}$

$\$ 100,000$

Miscellaneous Expense (Computer, etc.)

Personnel Costs (4)

(1) Two similar installations at LLL (1971-1972) averaged $\$ 130,000$ each. Present machine is smaller, but costs have inflated.

(2) Per year over $1 / 2$ year set-up $+1-1 / 2$ year operation.

(3) Based on assumed mass-production price. Present cost $=\$ 200 / 7$ iner in quantities of $3-5$, but these liners are double-ended.

${ }^{(4)}$ Salary, Overhead, burden, stores, minor procurements, travel - \$50K/FTE. 
Table IIIB

PHASE I (INITIAL EXPERIMENT): CAPACITOR BANK COMPRESSION

Facility Costs:

Use LLL Machine

Field Coils

3.4 MJ Capacitor Bank

Vacuum UV Diagnostics

Oscilloscopes, Screen Room

Machinè Shield + Installation

$$
\begin{gathered}
\$ 50,000 \\
1,100,000 \\
40,000 \\
85,000 \\
95,000 \\
\$ 1,370,000
\end{gathered}
$$

Personnel Required:

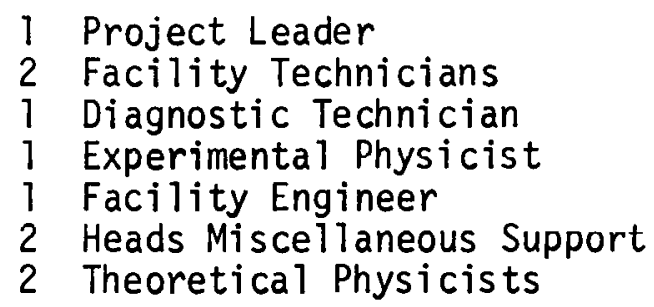

Estimated Operating Costs:

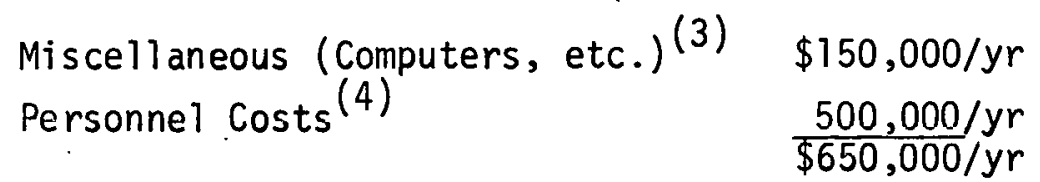

(1) Based on $500 \mathrm{kG}, 20 \mathrm{~cm}$ diameter, $10 \mathrm{~cm}$ long "force-free" coil design.

${ }^{(2)}$ Costs at $\$ 0.33 /$ joule (current LLL large-bank design figure).

(3) This approach, of course, uses no liners.

(4) Salary, overhead, burden, stores, minor procurements, travel $\$ 50 \mathrm{~K} / \mathrm{FTE}$. 
Table IVA

PHASE II (MAIN EXPERIMENT): $200 \mathrm{KJ}$ (MAGNETIC IMPLOSION OPTION)

Facility Costs:

$50 \mathrm{~kJ}-7.5 \mathrm{MeV}$ EB Machine (Installed)
$4400 \mathrm{~kJ}$ Implosion Bank
Diagnostic Equipment (Cameras, Scopes)
Shielding
Crane (2-ton)
Vacuum System and Coils
$1.35 \mathrm{MJ}$ Axial Current Bank$$
\begin{gathered}
\$ 500,000(1,2) \\
1,500,000(3) \\
75,000 \\
95,000 \\
10,000 \\
20,000 \\
445,000 \\
\$ 2,645,000
\end{gathered}
$$

Personnel :

1 Project Leader

3 Heads Miscellaneous Support

1 Facility Engineer

2. Facility Technicians

1 Diagnostic Technician

2 Experimental Physicists

2 Theoretical Physicists

4 Heads Engineering Design/Fabrication

Operating Costs:

Liners (100/year)

Expendables, Computer

Personnel Costs $(4)$
$\$ 200,000$

$150,000 / y r$

800,000

$\$ 1,150,000 / \mathrm{yr}$

(1) Based on 1972 costs for a similar installation, * 1.25 inflation.

(2) We could save $\$ 300 \mathrm{~K}$ if we can use DNA "Facility II" machine, currently housed at $P / I$.

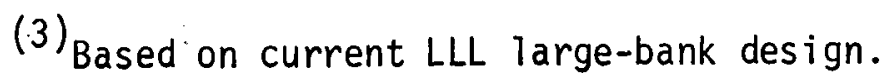

(4) Salary, overhead, burden, stores, minor procurement, travel - \$50K/FTE. 
Table IVB

PHASE II (MAIN EXPERIMENT): $200 \mathrm{KJ}$ (CHEMICAL IMPLOSION OPTION)

Facility Costs:

$500 \mathrm{KJ}$ System

$\begin{array}{lc}50 \mathrm{kj}-7.5 \mathrm{MeV} \text { EB Machine (Installed) } & \$ 500,000(1,2) \\ \text { Crane (5-ton) } & 25,000 \\ \text { Diagnostic Equipment } & 75,000 \\ \text { Shielding } & 95,000 \\ \text { Blast Containment } & 10,000 \\ \text { Vacuum System } & 10,000 \\ \text { Axial Current Bank } & 445,000 \\ & \$ 1,160,000\end{array}$

Personne]:

1 Project Leader

2 Heads Miscellaneous Support

1 Facility Engineer

2 Facility Technicians

1 Diagnostic Technician

2 Experimental Physicists

2 Theoretical Physicists

4 Heads Engineering Design/Fabrication

3 Heads HE Development

Operating Costs:

Expendab les, Computer

Personne1 Costs $(6)$

Bunker Charges (25 days)

HE Parts (100/yr)

$\$ 150,000$

Liners (100/yr)

900,000

HE Assembly (100/yr)

(1) Same basis as Table IVA.

(2) Assumes building available.

(3) Per D. Ravenscroft: 6 lbs HE, 2400 lbs steel, + fast-closing window.

(4) Per R. Anderson: 4 shots/day.

(5) Per J. Scudder: Experience with Roadrunner 4" ID $\times 18$ " long systems.

(6) $\$ 50 \mathrm{~K} / \mathrm{FTE}$, as in previous tables. 


\begin{tabular}{|c|c|c|c|c|}
\hline \multirow[b]{2}{*}{$\mathrm{T}_{0}(\mu \mathrm{sec})$} & \multicolumn{2}{|c|}{$\begin{array}{l}-31- \\
\text { TABLE V }\end{array}$} & \multirow[b]{2}{*}{$\tau(\mu \mathrm{sec})$} & \\
\hline & $V_{0}(\mathrm{~cm} / \mu \mathrm{sec})$ & ${ }_{C}^{\omega_{C}}(\mathrm{keV})$ & & $\underline{\lambda}$ \\
\hline 35.6 & 0.10 & 0.72 & 2.4 & 8.1 \\
\hline 20.0 & 0.18 & 1.25 & 1.2 & 9.3 \\
\hline 11.3 & 0.32 & 2.17 & 0.64 & 10.5 \\
\hline 6.33 & 0.56 & 3.72 & 0.34 & 11.8 \\
\hline 3.56 & 1.00 & 6.29 & 0.18 & 13.3 \\
\hline $2.00^{\circ}$ & 1.78 & 10.4 & 0.10 & 15.0 \\
\hline 1.13 & 3.16 & 16.8 & 0.06 & 16.3 \\
\hline 0 & $\infty$ & 100.0 & 0.014 & 20.0 \\
\hline
\end{tabular}

Similar to Tables I and II except that the above values are for a weak E-layer with initial conditions given in Sec. VIII. 


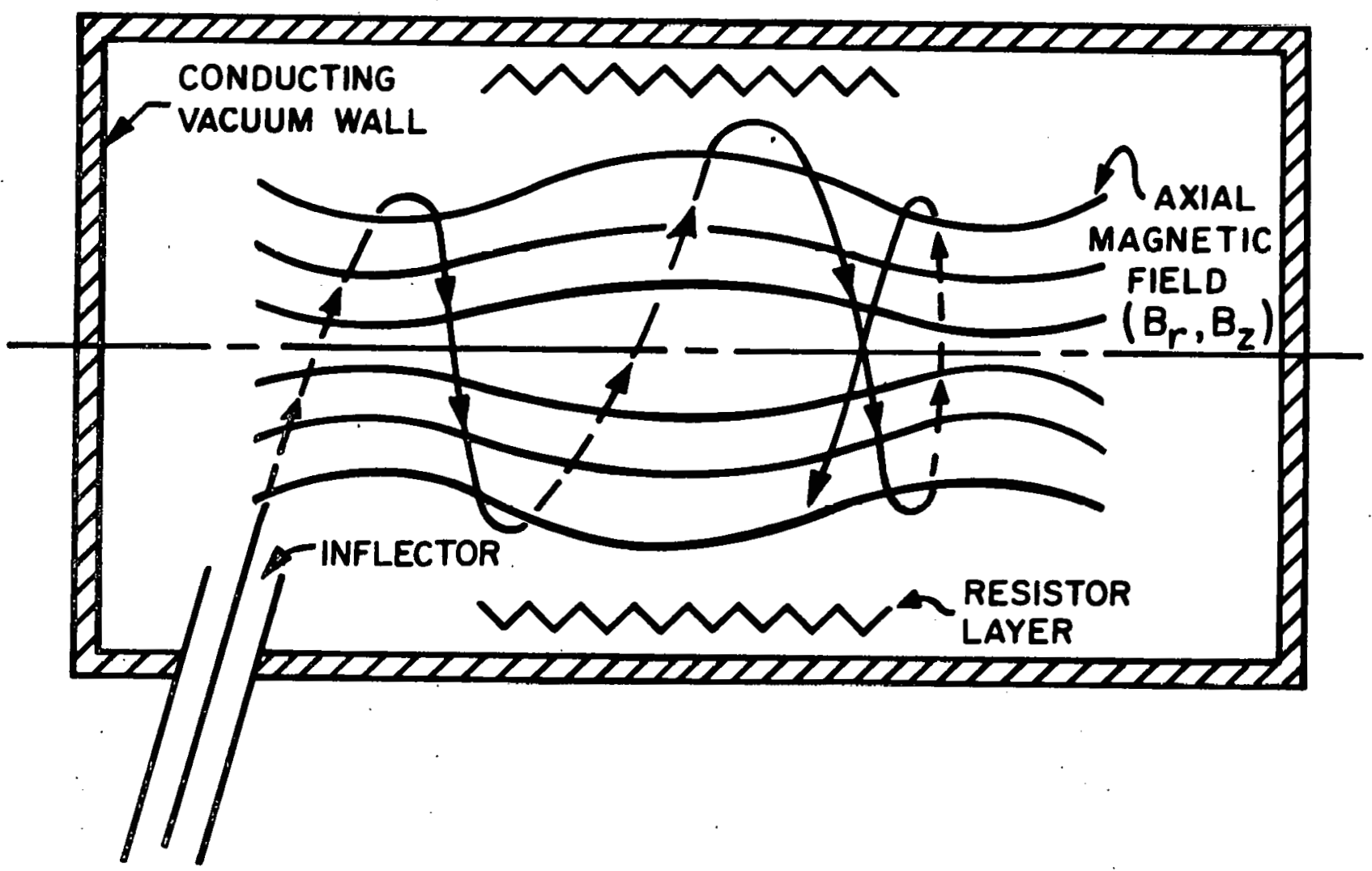

Figure 1

INJECTION and TRAPPING OF E-LAYERS 


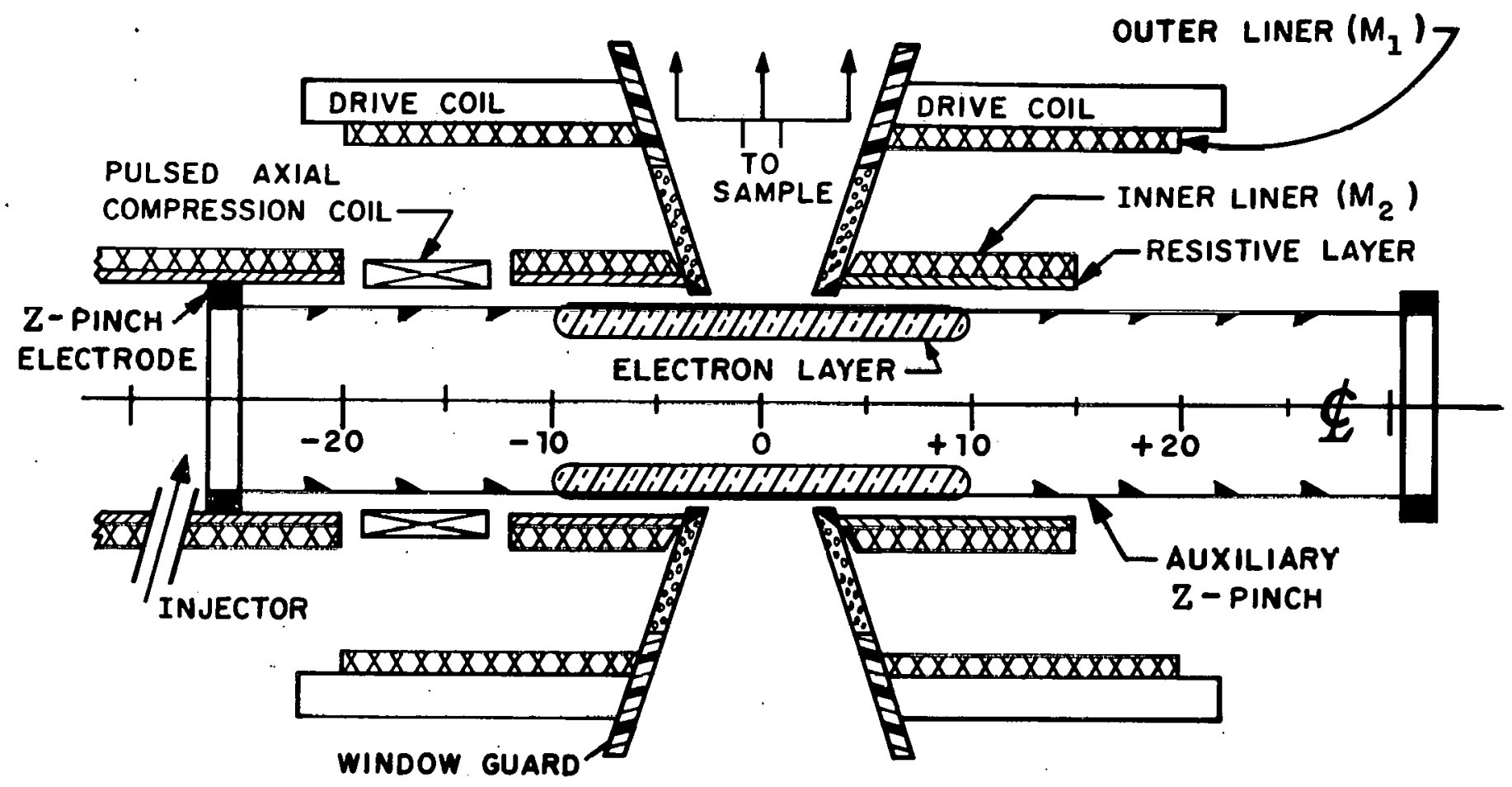

Figure 2a

\section{IMPLODING LINER SYNCHROTRON EMISSION SOURCE}




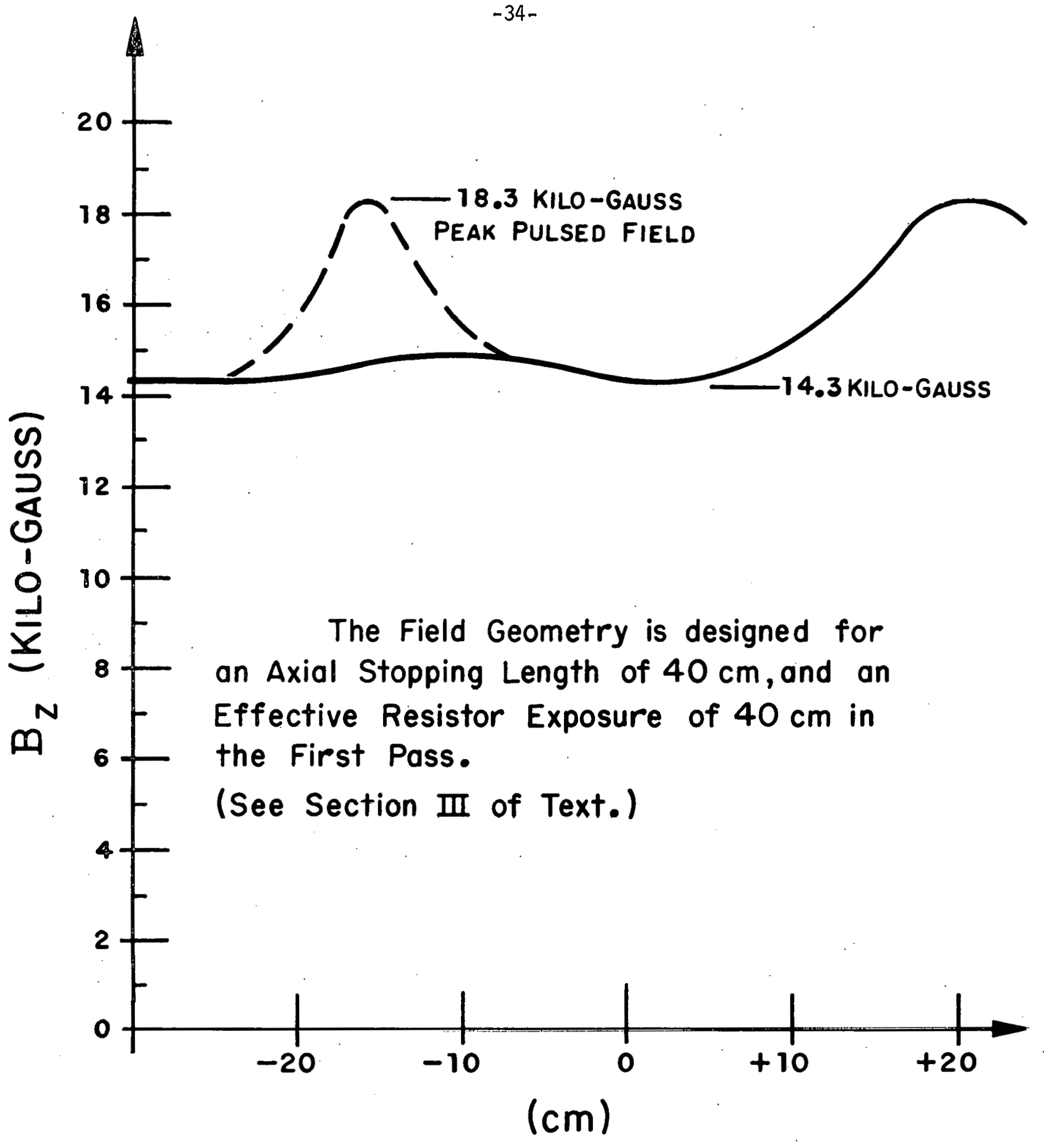

Figure 2b

MAgnetic PROfiles fOR Fig.2a 
FINAL STATE

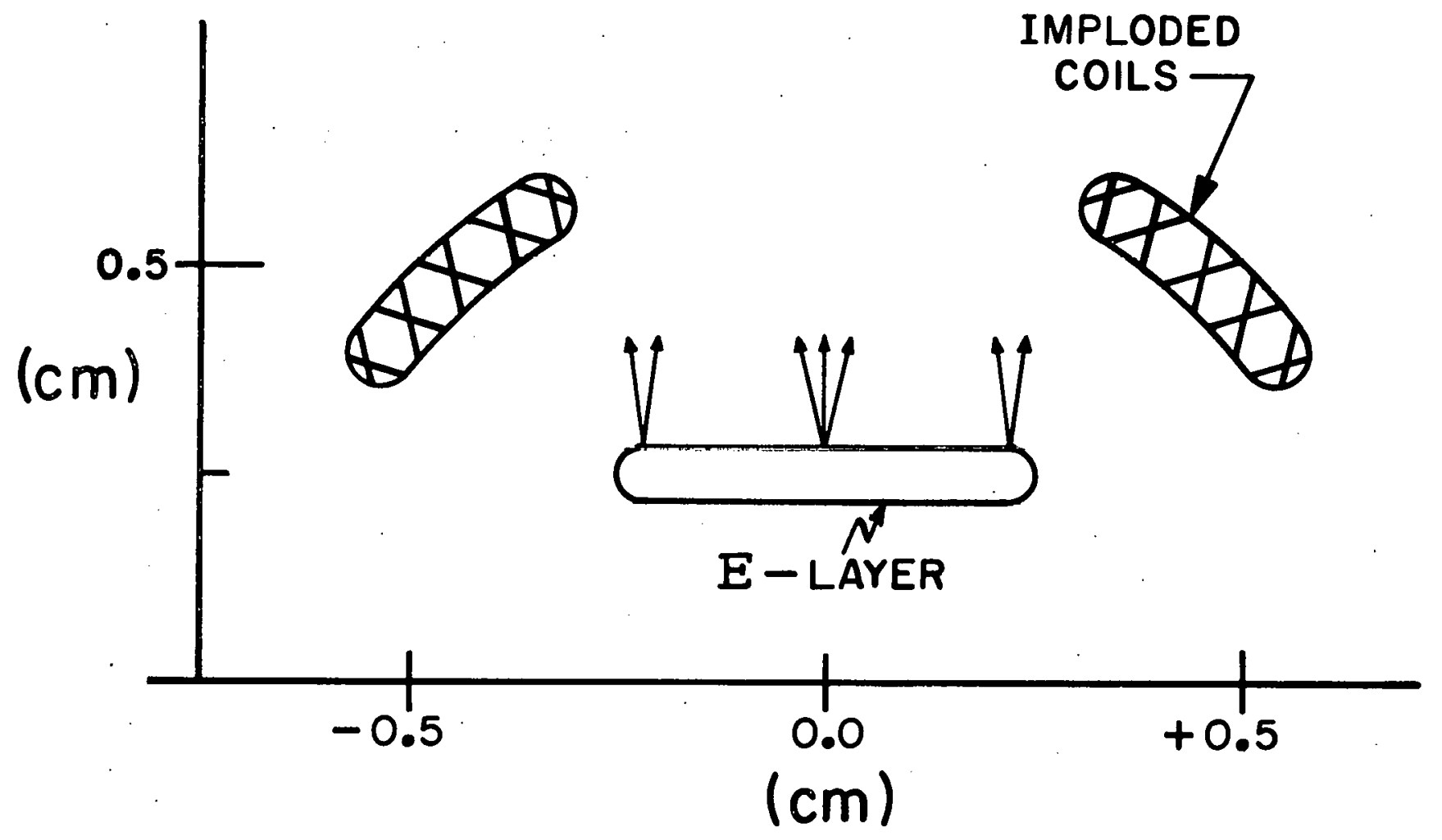

Figure 2c

Final State of LAyer Compressed BOTH AXIALLY AND RADIALLY. Note RELATIVE ANGULAR SPREAD OF PHOTON EMISSION FROM CENTER AND ENDS. 


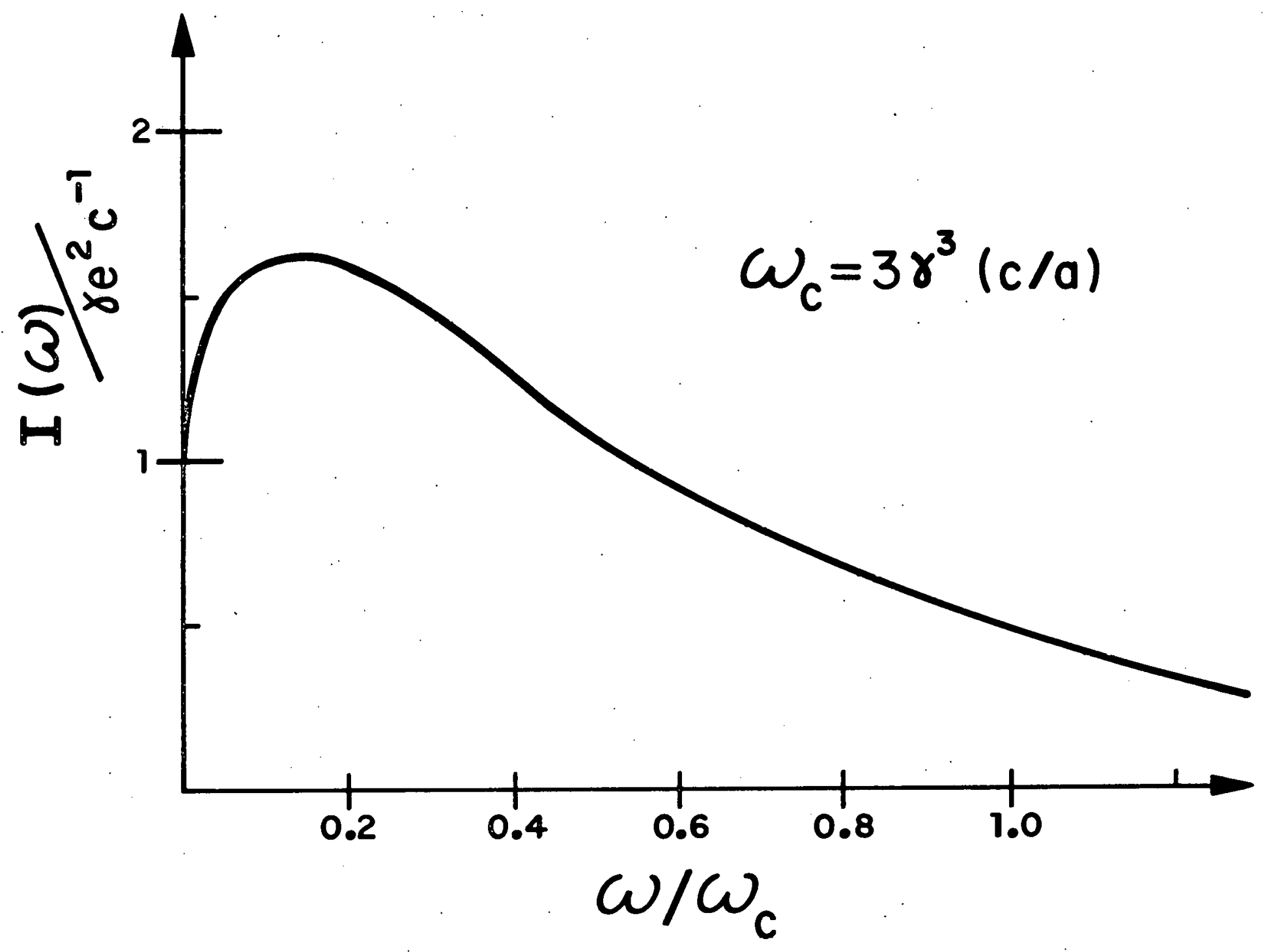

Figure 3

\section{SYNCHROTRON SPECTRUM}




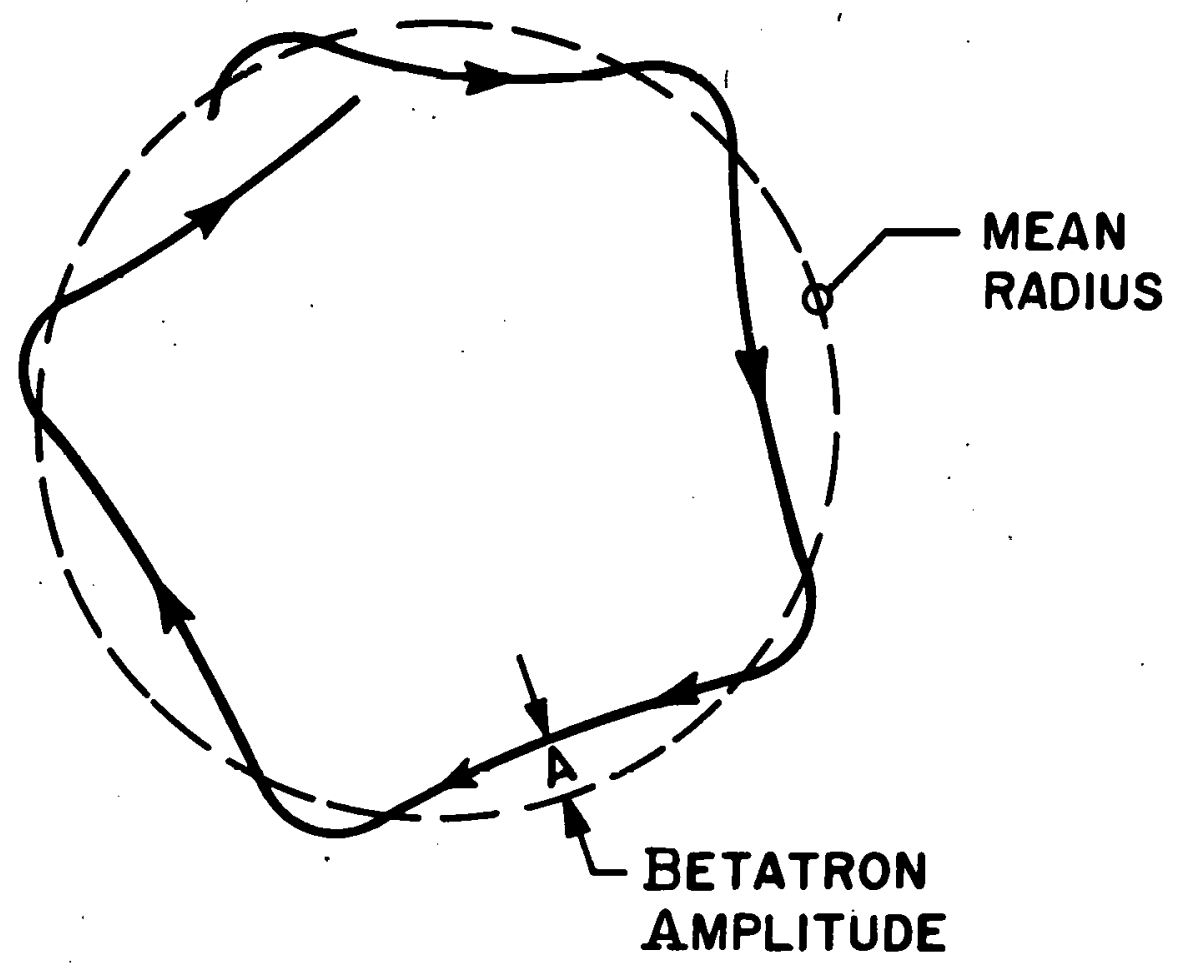

Figure 4

RADIAL BETATRON OSCILLATIONS

We have Assumed $\zeta_{\text {net }}>1$, so the trajectories have NegATIVE CuRVATURE INSIDE THE ORBIT. 


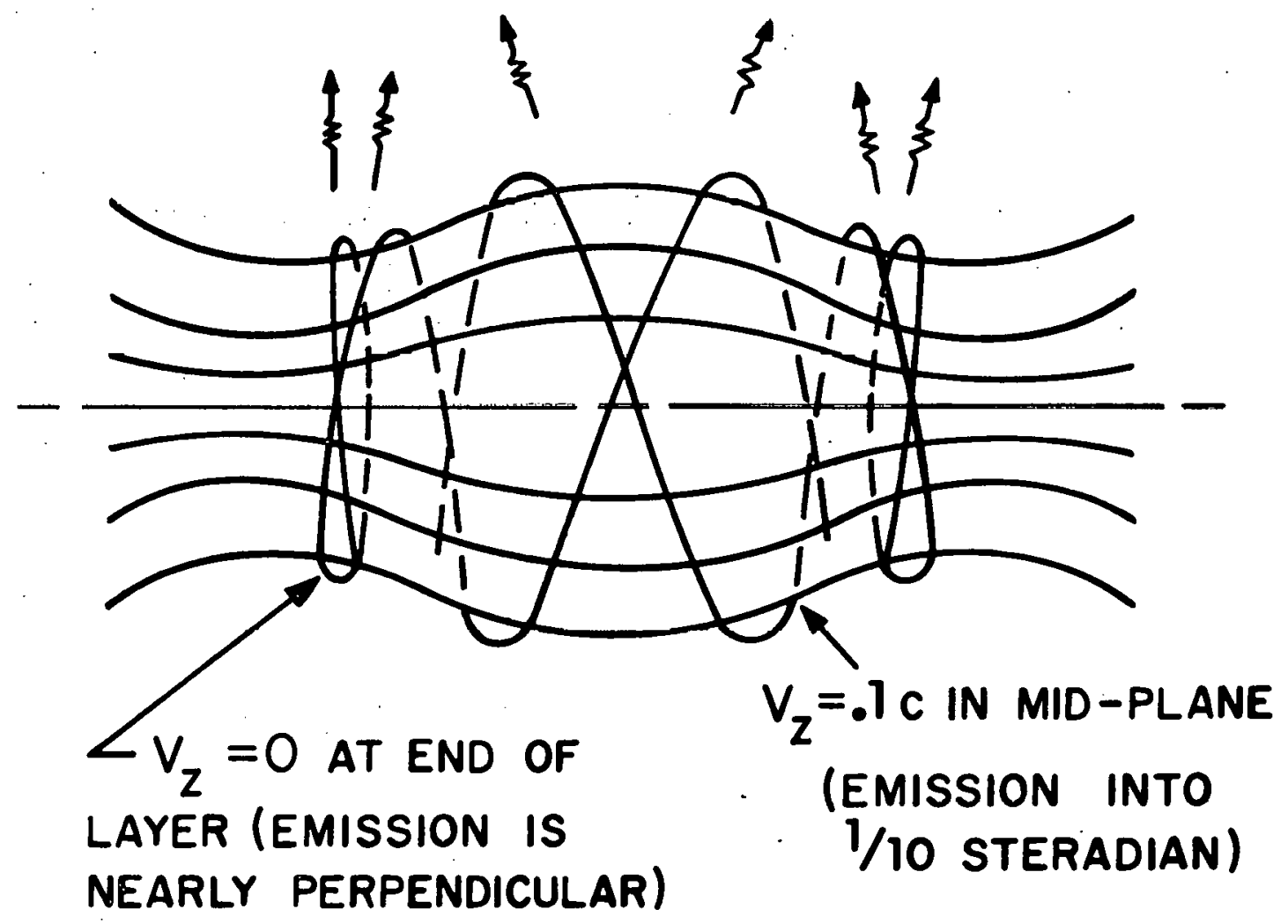

Figure 5

EFFECT OF AXIAL BETATRON

OSCILLATIONS ON SYNCHROTRON EMISSION ANGLE 
(a) TEARING

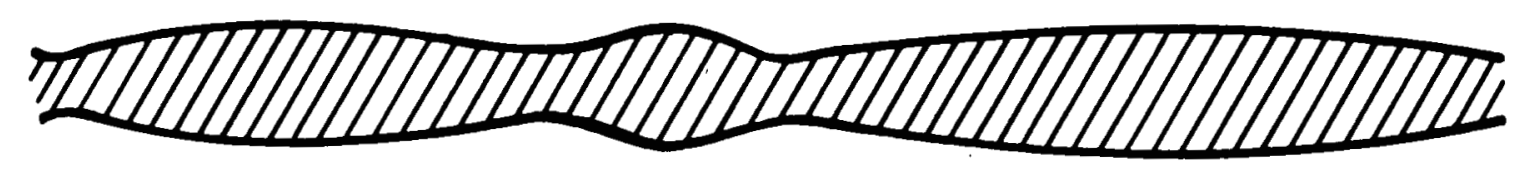

(b) SEPARATED

(1)
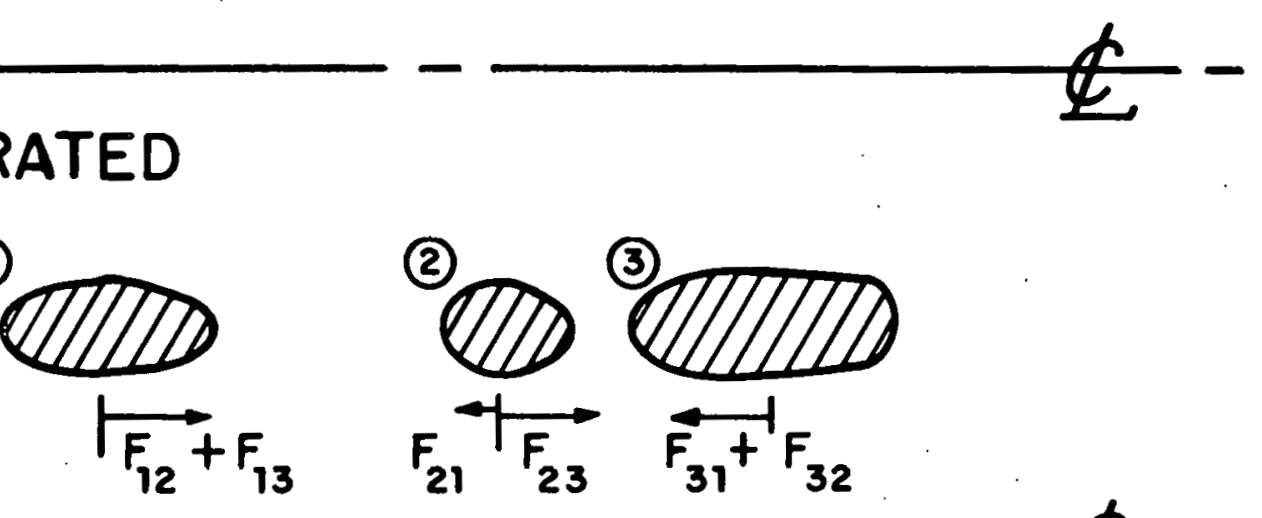

(c) COALESCED

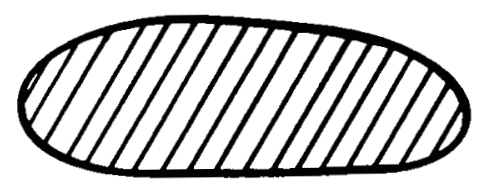

Figure 6

\section{TEARING INSTABILITY}

The effect is due to AXIAL ATTRACTION between different parts of the LAYER. 


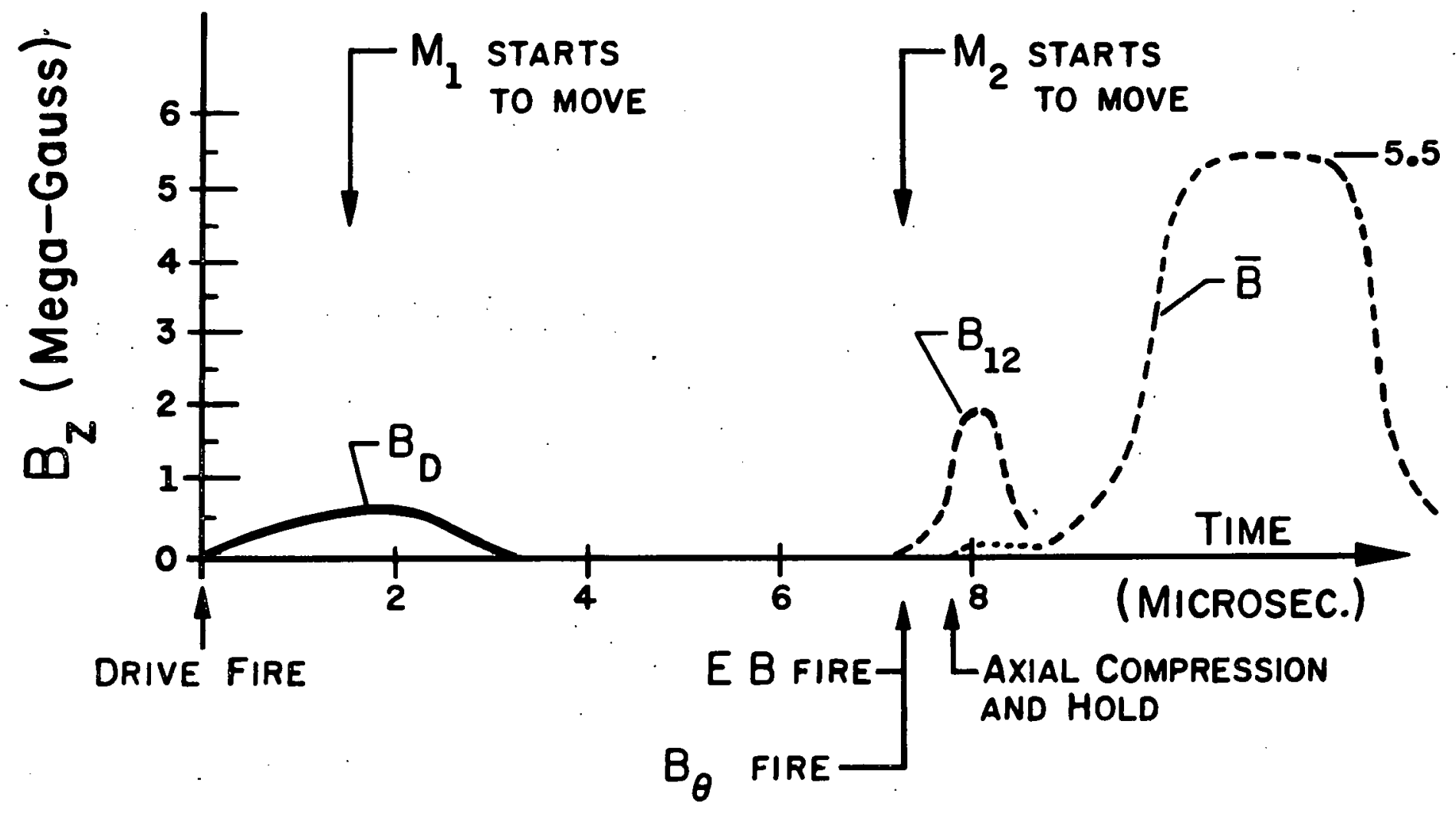

Figure 7

TIME VARIation of Axial Magnetic FIELDS FOR CASE II.5.b (TWO STAGE)

$B_{D}=$ DRIVE FIELD

$B_{12}=$ FIELD BETWEeN $M_{1}$ and $M_{2}$

$\bar{B}=$ FIELD INSIDE LINER 


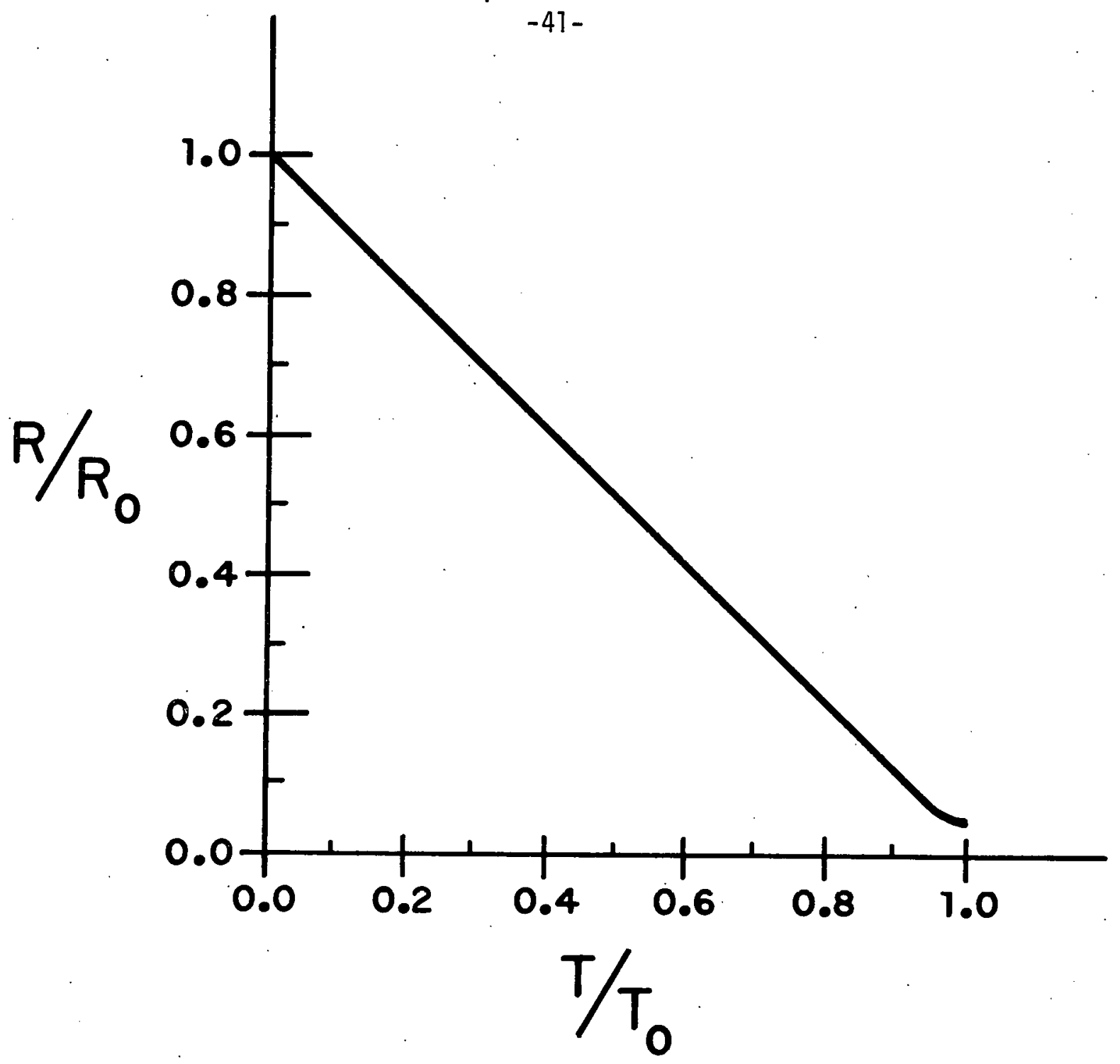

Figure 8

$R / R_{0}$ vs. $T / T_{0}$

FOR "IDEALIZED" IMPLOSION OF LINER

BY MAGNETIC FIELDS

$\frac{R_{\text {INITIAL }}}{R_{\text {FINAL }}}=20$

FINAL 


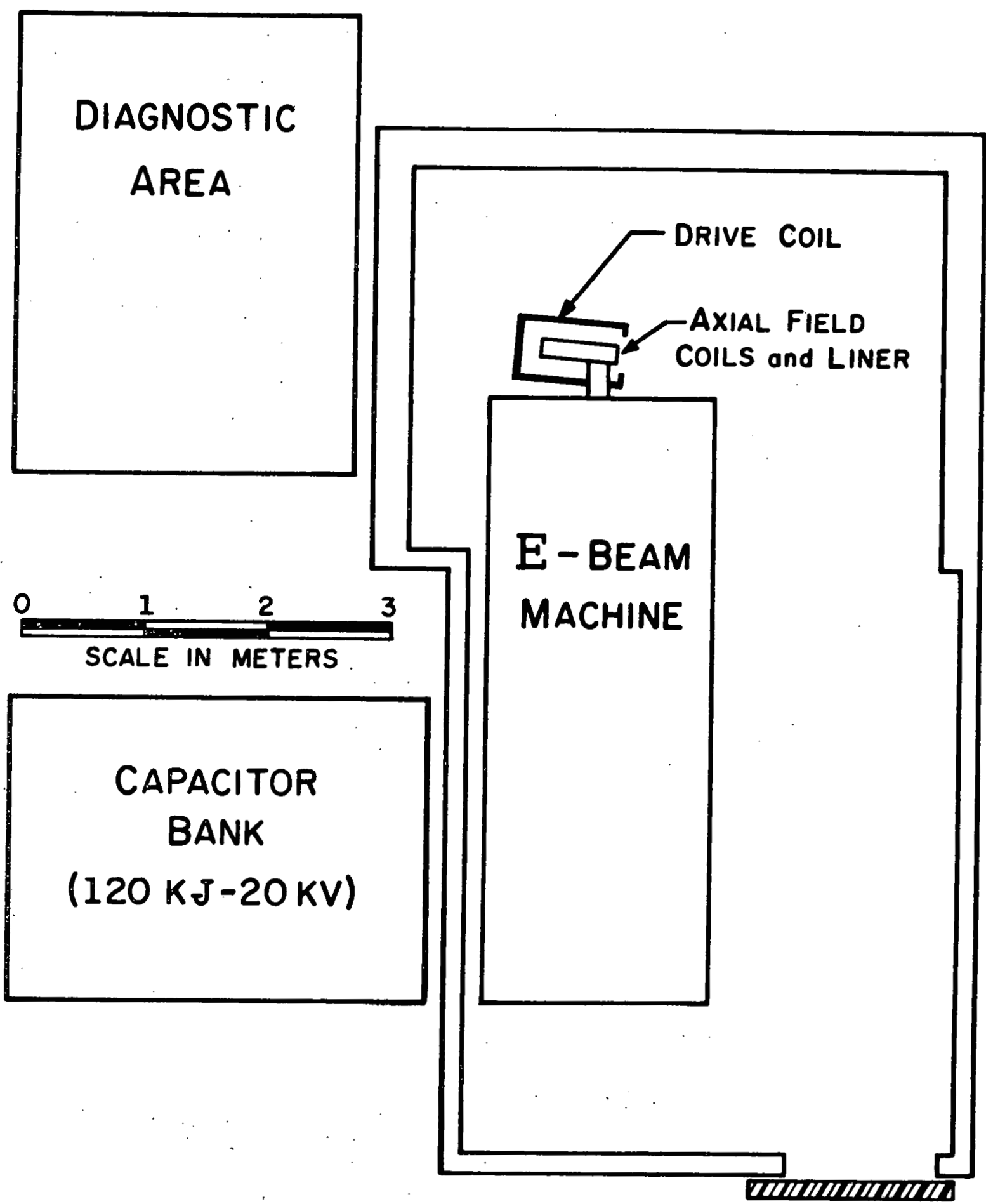

Figure 9 

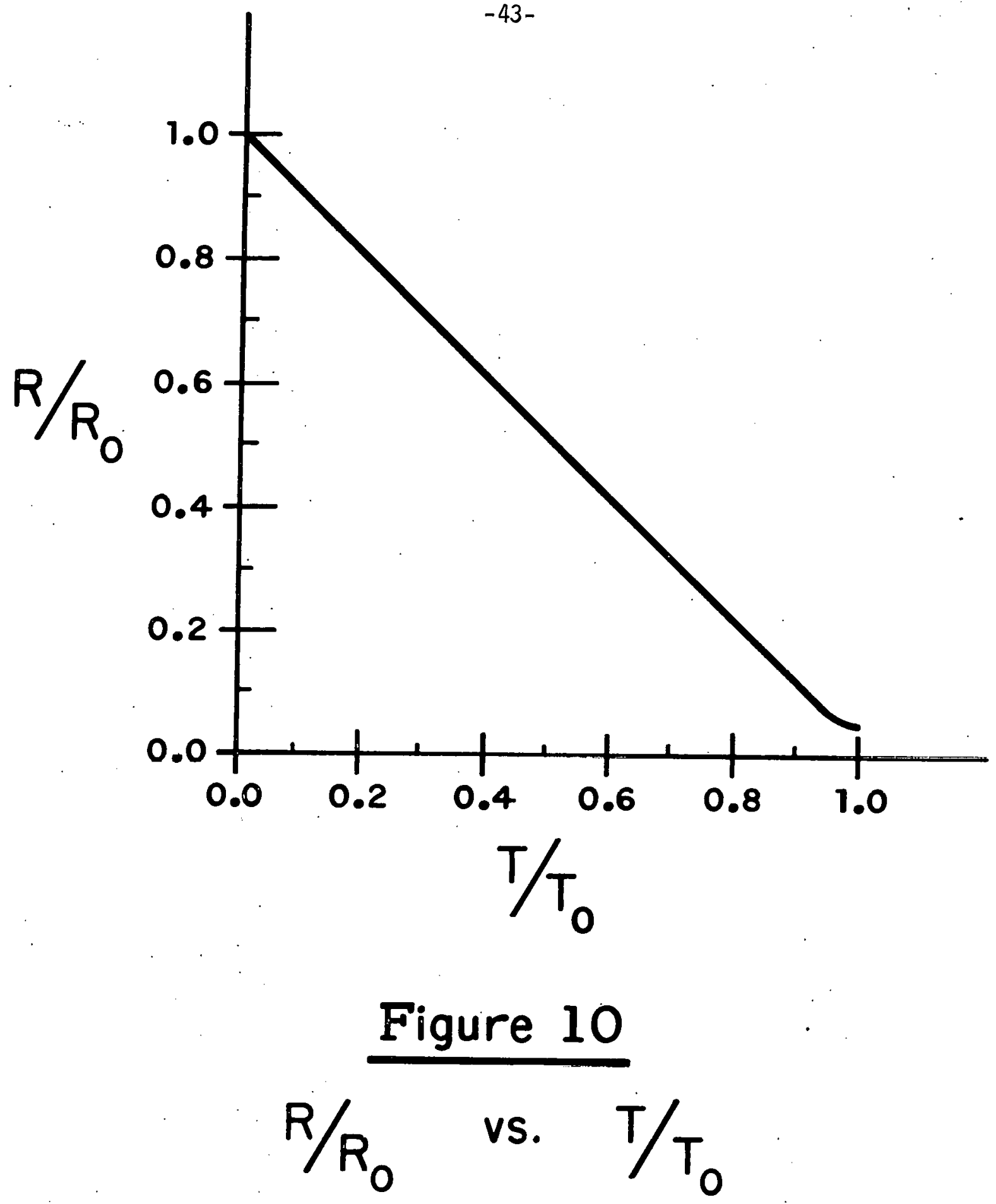

FOR "IDEALIZED" IMPLOSION OF LINER BY MAGNETIC FIELDS $\frac{R_{\text {INITIAL }}}{R}=20$

FINAL 


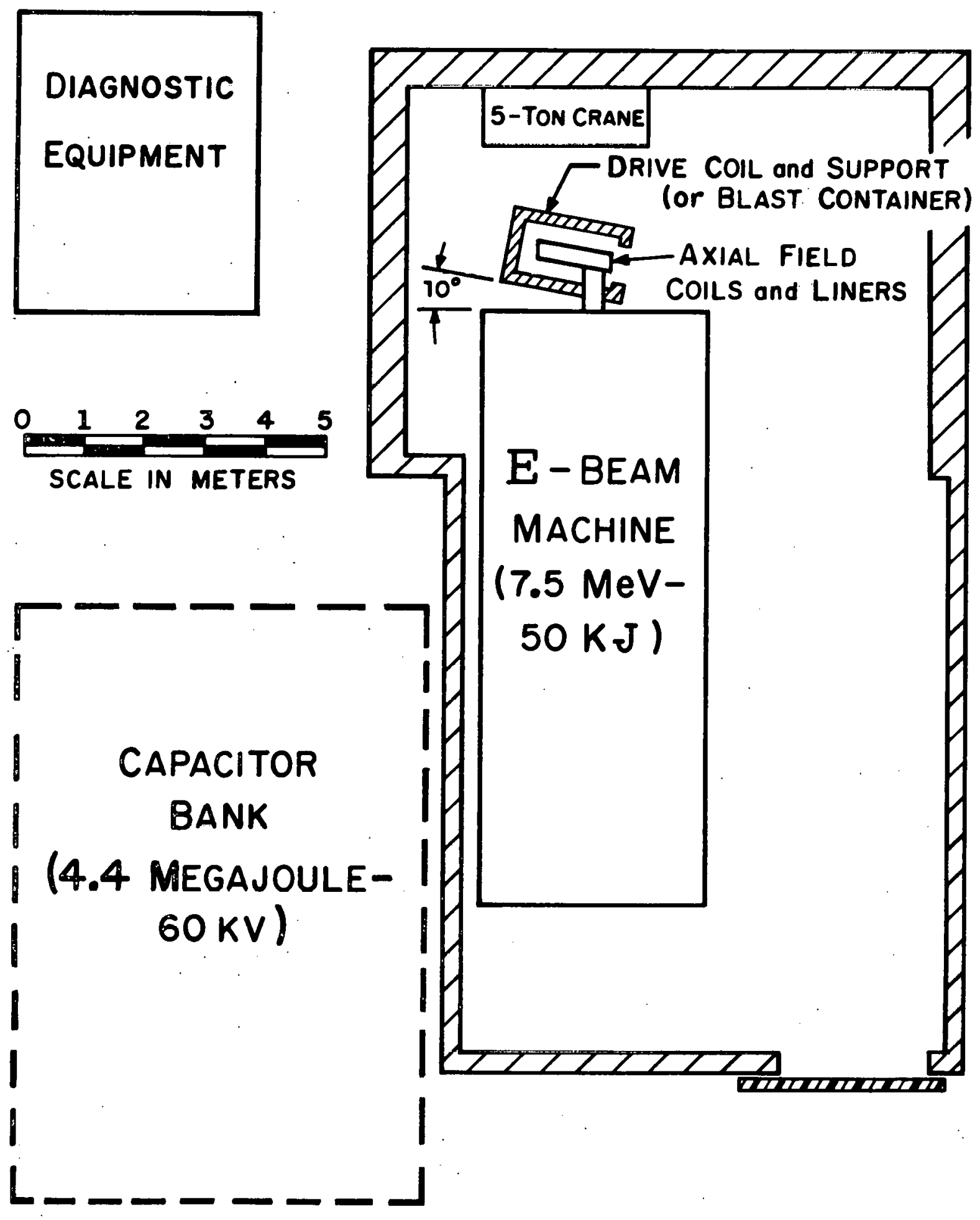

Figure 11 


\section{APPEINDIX A}

We are interested in the retarding forces acting on an e-layer. For a single electron at the front of the e-layer (moving in the positive $z-$ direction) the force is given by

$A-1 \quad F_{z}=q\left[\bar{E}+\frac{\bar{V}_{\perp} \times \bar{B}}{C}\right]_{z}$

where the background magnetic field is in the z-direction. If nearly complete current neutralization is assumed we have the following expressions for the return current in the background plasma $\mathrm{J}_{\mathrm{p}}$

$A-2 a \quad J_{p \theta}=-J_{b \theta}$

$A-2 b \quad J_{p z}=-J_{b z}$

where the subscript $b$ represents the current in the e-layer. We further assume that

$A=3 \quad J_{b, p} \sim J_{b} p\left(z-v_{1}, t\right)$

this allows us to replace $\frac{\partial}{\partial t}$ by $-V_{1}, \frac{\partial}{\partial z}$ in Maxwell's equations. Utilizing

Ohm's law we replace $E_{2}$ in $E q$. A-l by $J_{11} / \sigma_{11}$, where $J_{11}$ is the return current in the plasma, and $\bar{V}_{\perp} \times \bar{B}$ by $-V_{\perp} B_{r} \cdot B_{r}$ is calculated from Maxwe li's equations as follows:

A-4 $(\bar{\nabla} \times \bar{J} / \sigma)_{r}=-\frac{1}{c} \frac{\partial B_{r}}{\partial t}=-\frac{\partial}{\partial z} \quad\left(J_{\perp} / \sigma_{\perp}\right)=\frac{V_{11}}{c} \frac{\partial B_{r}}{\partial z}$

then we have

$A-5$

$$
B_{r}=-\frac{J_{\perp}}{\sigma_{\perp}} \frac{c}{V_{11}}
$$


thus Eq. A-1 becomes

A-6 $\quad F_{2}=q\left[\frac{J_{11}}{\sigma_{11}}+\frac{J_{\perp}}{\sigma_{\perp}} \frac{V_{1}}{V_{11}}\right]$

this is essentially the Chu-Rostoker result, ${ }^{13}$ with the exception that they derive the expressions for $\sigma_{11}$ and $\sigma_{\perp}$ as well. We assume $\sigma_{11}=1.97 \sigma_{\perp}$, following Spitzer. ${ }^{29}$ In terms of the primary layer current, $J_{11}$ and $J_{\perp}$ can be expressed as

A-7

$$
J_{11}=-\frac{N^{\prime} q V_{11}}{2 \pi R D}
$$

and

A-8

$$
J_{\perp}=-\frac{N^{\prime} q V_{\perp}}{2 \pi R D}
$$

where $R$ is the radius of the layer, $D$ the thickness, $q$ the charge, and $N^{\prime}$ the number of charges per unit length. Substituting in Eq. A-6 we have

A-9

$$
F_{z}=-\frac{W^{\prime} q^{2} V_{11}}{2 \pi R D}\left[\frac{1}{\sigma_{11}}+\left(\frac{V_{1}}{V_{11}}\right)^{2} \frac{1}{\sigma_{1}}\right]
$$

Equation $A-9$ is valid only if

A- 10

$$
\frac{4 \pi \sigma_{\perp} D^{2}}{c^{2}}>\frac{D}{V_{11}}
$$

where the L.H.S. of Eq. A-10 represents the time for the return current to diffuse a distance $D$.

Equation A-9 represents the force on an electron at the front of the e-layer. The characteristic stopping distance is computed by setting the

$$
\text { RANGE }=\frac{r m_{0} V_{11}{ }^{2}}{2 F_{z}} \text {. }
$$


Chu-Rostoker ${ }^{13}$ have evaluated the above in terms of the particle densities and the collision frequencies. Noting that $\sigma_{11}=n_{0} e^{2} \tau_{e} / m_{e}$, we get Eq. III.l of the text, with $n_{b}=N^{\prime} / 2 \pi R D$. We note that the right-hand side contains the ratio $\nu_{\mathrm{e}} / \mathrm{n}_{0}$, which is a function of temperature only. 29 For our test case $\left(\gamma_{i}=16.1, \zeta=13.2, R_{i}=2 \mathrm{~cm}, D=.4 \mathrm{~cm}, L=20 \mathrm{~cm}\right)$, the temperature of $8.3 \mathrm{eV}$ gives a value of $R=40 \mathrm{~cm}$. Condition $A-10$ is well satisfied: LHS $=448 \mathrm{~ns}$, which is the time for the field to show through. We chose $n_{0}=20, n_{p}=15.2 * 10^{14} / \mathrm{cc}$ as being dense enough to easily neutralize the beam. Then $\nu_{e}=1.03 * 10^{9} / \mathrm{sec}$. Due to the large heating rate, the initial plasma temperature can be somewhat lower than $8 \mathrm{eV}$. This effect needs calculational effort. 


\section{APPENDIX B}

\section{Precessional Stability Calculations}

The precessional instability can be suppressed either by the presence of conducting walls (for incomplete current neutralization) or by a toroidal field from the current in a central wire. Since a central wire introduces mechanical complications, we first examine the wall stabilization.

The precession frequency is

B-1 $\quad \omega_{p}=\frac{1}{2} \omega_{c}\left(\left|n_{M}\right|-n_{i}\right)$

Here $\omega_{c}$ is the cyclotron frequency, and the $n^{\prime} s$ are the logarithmic radial field derivatives, $d$ en $B_{z} / d$ en $R$, from the external mirror and the image currents in the wall, respectively. If $\omega_{p}>0$, the precession is unstable. 6

For the mirror field we assume the simple form $B_{z}=B_{0}+2 b z^{2}-b r^{2}$, which, with $B_{r}=-2 b r z$ yields a curl-free and divergence-free mirror for positive b. From Fig. 2b, we want $B_{z} / B_{0}=1.333$ at $z=10 \mathrm{~cm}$. This yields $b=1.667 * 10^{-3} B_{0}$, and $n_{M}=-2 b R^{2} / B_{0}$. For $R=2 \mathrm{~cm}$ from II.5.b, we get

$$
\eta_{M}=-.01333
$$

The image current contribution is evaluated using the notation of Ref. 6 .

B- 3

$$
n_{i}=\frac{(k R)^{2} \zeta\left(\psi_{1}+\psi_{2}\right)}{4\left(1+k^{2} / k_{0}^{2}\right)\left[J_{0}\left(k_{0} R_{0}\right)-J_{0}\left(k_{0} R_{i}\right)\right]}
$$


where $k=2 \pi / L$ for the layer, $\zeta$ is defined in Section II, and $k_{0}$ sets the radial thickness $\left(k_{0} R_{j}, k_{0} R_{0}\right.$ are adjacent zeroes of the $J_{1}$ function). The $\psi^{\prime} s$ are functions of $k R_{0}$ and $k R_{j}$. The layer is assumed to have a $J_{1}\left(k_{0} r\right)$ current density profile between $R_{j}$ and $R_{0}$ and to be zero elsewhere. $R$ is the radius of peak current density, taken as $2 \mathrm{~cm}$ from II.5.b. Picking the fourth zero of $J_{1}^{\prime}$, we get $k_{0} R_{0}=11.706$. The rest of the parameters follow:

B-4

$$
\begin{aligned}
k & =.314159 \mathrm{~cm}^{-1} \\
k_{0} & =5.853 \mathrm{~cm}^{-1} \\
k_{0} R_{j} & =10.1735 \text { or } R_{j}=1.738 \\
k_{0} R_{0} & =13.3237 \text { or } R_{0}=2.276
\end{aligned}
$$

We choose $R_{W}=\sqrt{2} R$, and tabulate the quantities needed ${ }^{6}$ in computing $\psi_{1}$ and $\psi_{2}$ :

$$
\text { B-5. } \begin{aligned}
k R_{i} & =.5460 \\
k R_{0} & =.7150 \\
k R_{W} & =.8886
\end{aligned}
$$

From this we compute $\phi_{1}=3.501, \phi_{2}=0$ (notation of Ref. 6). We, also need the following quantities:

B-6

$$
\begin{aligned}
& I_{1}\left(k R_{0}\right)=.3806 \\
& I_{1}\left(k R_{j}\right)=.2826 \\
& J_{0}\left(k_{0} R_{0}\right)=+.21836 \\
& J_{0}\left(k_{0} R_{j}\right)=-.24970
\end{aligned}
$$

We do not need the $K$ functions since $\psi_{2}$ is proportional to $\phi_{2}$ and hence zero. 
Evaluating from Ref. 6, Eq. III.24, we get $\psi_{1}=3.501$. Using this in $B-3$ we find

B-7

$$
\eta_{i}=.2877 \zeta
$$

Equating this to $n_{M}$ from $B-2$, we find the critical $\zeta$ for stability:

B-8

$$
\zeta_{c}=.046
$$

This is trivially achieved. Shortening the layer during the axial compression raises the value of $\zeta_{c}$, however, and one should note that it is the net $\zeta$ which counts in stabilizing the precessional mode. In a hot plasma, the net $\zeta$ is not easily controlled. For this reason we continue to consider the possibility of having a small center rod in the device, as discussed in the text. This has the additional effect of making $\phi_{2} \neq 0, \psi_{2} \neq 0$, so that additional stabilization is obtained. 


\section{APPENDIX C}

The magnetic energy content of the system was calculated by considering the self-inductance of two square coils of thickness $6 \mathrm{~mm}$ separated by a center-to-center distance of $1.5 \mathrm{~cm}$ with a mean radius of $0.5 \mathrm{~cm}$. The current was calculated by assuming a field of $5.5 \times 10^{6}$ gauss at the midpoint of the rings. This procedure yielded a value of $900 \mathrm{~kJ}$. Two other values of interest are the energy stored in a region $1.5 \mathrm{~cm}$ long and 0.5 $\mathrm{cm}$ in radius which is given by

$$
E_{\text {uniform field }}=142 \mathrm{~kJ} \quad(5.5 \text { megagauss })
$$

and the energy stored in a solenoid $1.5 \mathrm{~cm}$ long with radius $0.5 \mathrm{~cm}$. The latter is given by

$$
E_{\text {solenoid }} \cong 474 \mathrm{~kJ} \quad(5.5 \text { megagauss midplane })
$$

The actual choice of the arrangement of the magnetic fields coils will in part be determined by stability conditions.

The magnetic field at either ring is stronger by a factor $.5\left(a^{2}+z^{2}\right)^{3 / 2} / a^{3}=2.9$. This gives a field of 16 megagauss inside either ring, and the nonlinear skin effect permits the field to diffuse about 1 millimeter into the $6 \mathrm{~mm}$ thick coil during the $100 \mathrm{~ns}$ peak field period. 
DISTRIBUTION

\author{
External \\ John Farber \\ Peter Haas \\ David Oakley \\ Gordon Soper \\ Defense Nuclear Agency \\ Washington, D.C. 20305 \\ Dr. Jack Rosengren \\ Dr. B. Hartenbaum \\ Dr. C. A. McDonald \\ $R$ \& D Associates \\ Santa Monica, Cálifornia 90403 \\ Dr. L. Levine \\ Dr. A. E. Robson \\ Dr. P. Turchi \\ Naval Research Laboratory \\ Washington, D. C. 20375
}

\title{
Internal
}

W. C. Condit $(A / L-33)$

E. K. Freytag (EE/L-153)

E. Garel is $(A / L-33)$

B. C. Groseclose (Director's office/L-2)

W. A. Lokke $(A / L-33)$

D. A. Nowak $(A / L-33)$

J. W. Shearer $(M / L-387)$

P. C. Wheeler (Nuclear Explosives/L-21)

TID Files (L-9) (5)

A-Division Files (L-33) (20)

"This report was prepared as an account of work sponsored by the United States Government. Neither the United States nor the United States Atomic Energy Commission, nor any of their employees, nor any of their contractors, subcontractors, or their employees, makes any warranty, express or implied, or assumes any legal liability or responsibility for the accuracy, completeness or usefulness of any information, apparatus, product or processs disclosed, or represents that its use would not infringe privatelyowned rights." 